\title{
Mechanisms of Aberrant Organization of Growth Plates in Conditional Transgenic Mouse Model of Spondyloepiphyseal Dysplasia Associated with the R992C Substitution in Collagen II
}

\author{
Machiko Arita, Jolanta Fertala, Cheryl Hou, Andrzej Steplewski, and Andrzej Fertala
}

From the Department of Orthopaedic Surgery, Sidney Kimmel Medical College, Thomas Jefferson University, Philadelphia, Pennsylvania

Accepted for publication

September 3, 2014.

Address correspondence to Andrzej Fertala, Ph.D., Department of Orthopaedic Surgery, Sidney Kimmel Medical College, Thomas Jefferson University, Curtis Bldg., Room 501, 1015 Walnut St., Philadelphia, PA 19107. E-mail: andrzej fertala@jefferson.edu.

\begin{abstract}
Mutations in collagen II, a main structural protein of cartilage, are associated with various forms of spondyloepiphyseal dysplasia (SED), whose main features include aberrations of linear growth. Here, we analyzed the pathomechanisms responsible for growth alterations in transgenic mice with conditional expression of the R992C collagen II mutation. Specifically, we studied the alterations of the growth plates of mutant mice in which chondrocytes lacked their typical columnar arrangement. Our studies demonstrated that chondrocytes expressing the thermolabile R992C mutant collagen II molecules endured endoplasmic reticulum stress, had atypical polarization, and had reduced proliferation. Moreover, we demonstrated aberrant organization and morphology of primary cilia. Analyses of the extracellular collagenous deposits in mice expressing the R992C mutant collagen II molecules indicated their poor formation and distribution. By contrast, transgenic mice expressing wild-type collagen II and mice in which the expression of the transgene encoding the R992C collagen II was switched off were characterized by normal growth, and the morphology of their growth plates was correct. Our study with the use of a conditional mouse SED model not only indicates a direct relation between the observed aberration of skeletal tissues and the presence of mutant collagen II, but also identifies cellular and matrix elements of the pathomechanism of SED. (Am J Pathol 2015, 185: 214-229; http://dx.doi.org/ 10.1016/j.ajpath.2014.09.003)
\end{abstract}

In the mature skeleton, collagen II is the most abundant structural protein of the cartilaginous tissues. ${ }^{1-3}$ This protein assembles into heterotypic fibrils, which in association with other proteins and proteoglycans form a complex extracellular scaffold able to withstand the mechanical forces imposed on it. ${ }^{4,5}$ During skeletal development, collagen II plays a critical role in the embryonic cartilaginous skeleton, a tissue whose elements are highly organized into a fibrillar collagenous network that interlaces with noncollagenous elements. Collagen II is not only essential for the structural integrity of the growing skeleton, but it also functions as an element of a complex framework that facilitates the specific three-dimensional organization of chondrocytes. The correct arrangement of chondrocytes provides a blueprint for the elongation of bones whose growth is a result of endochondral ossification. 6,7 One characteristic that defines properly organized chondrocytes in a postnatal growth plate is their columnar arrangement. Within individual columns, distinct subpopulations of chondrocytes form the resting, the proliferating, the prehypertrophic, and the hypertrophic zones. This organization is a result of complex processes that include the division of chondrocytes and rotations of daughter cells to form typical columns. ${ }^{8,9}$ These complex processes depend not only on the correct structure of the extracellular scaffold that guides the organization of chondrocytes, but also on the ability of these cells to sense and correctly interact with this biological framework. It has been

\footnotetext{
Supported by intramural funding provided by the Department of Orthopaedic Surgery, Sidney Kimmel Medical College, Thomas Jefferson University, Philadelphia, PA.

M.A. and J.F. contributed equally to this work.

Disclosures: None declared.
} 
determined that those critical interactions are mediated in part by the primary cilia, specialized cell surface projections able to transduce mechanical and chemical signals from surrounding extracellular matrix $(\mathrm{ECM}) \mathrm{s}^{8,10^{-13}}$ Specific receptors present on the surfaces of primary cilia facilitate primary cilia-matrix interactions. ${ }^{14}$

A key role of collagen II in the ECM of growing bones is illustrated by the fact that mutations in collagen II alter bone development ${ }^{15}$ and produce a broad spectrum of chondrodysplasia phenotypes that fall under the general designation SED (Online Mendelian Inheritance of Man no. 183900; http://www.ncbi.nlm.nih.gov/omim). SED variants range in severity from achondrogenesis type II, which is lethal at or before birth, to late-onset SED, the main feature of which is precocious osteoarthritis. ${ }^{15}$ Molecular pathomechanisms of SED are complex and may include misfolding of mutant collagen II molecules, changes in their physicochemical properties, and formation of abnormal collagen II fibrils. In addition, mutations in collagen II molecules may lead to their excessive intracellular accumulation, thereby triggering endoplasmic reticulum (ER) stress. ${ }^{15}$

Although the consequences of collagen II mutations have been studied in vitro and ex vivo in isolated mutant molecules in cells harboring them, the effect of mutations in collagen II in the dynamic context of the skeletal tissues is still not well understood. Because opportunities for carrying out detailed studies of the molecular and cellular processes in SED patients are limited, a number of transgenic mice harboring collagen II mutations were generated to create SED-like models. ${ }^{16-19}$ Although the mouse-based models do not fully replicate all aspects of human SED, using these models was crucial to discovering organ-level pathological characteristics of affected bones such as the disorganization of growth plates, aberrations of collagen fibrils, and alterations of cell functions.

Here, we present a study focusing on the pathomechanisms of a relatively mild form of SED associated with the R992C collagen II mutation expressed in the transgenic mouse model. The R992C mutation was first described as a spontaneous point mutation causing an amino acid substitution in mice with SED-like features that comprised alterations of skeletal growth and disorganization of the growth plates. ${ }^{20}$ Subsequently, using a technology for the production of recombinant collagen II molecules in a cell-based expression system, we determined that the R992C mutations are characterized by low thermostability. ${ }^{21}$ Moreover, using ex vivo cell-based systems to generate organotypic cartilage-like constructs, we demonstrated that the excessive intracellular accumulation of the R992C mutant molecules is associated with ER stress. ${ }^{21,22}$

The SED model presented here was created to allow conditional expression of the mutant or the wild-type (WT) transgene by using a tetracycline (Tet)-modulated promoter so that in the presence of tetracycline or its analog doxycycline (Dox), the expression of the transgene is blocked (Tet-off). We demonstrated that in the presence of the
R992C collagen II molecules, the mice develop skeletal aberrations that include alterations of the linear growth. Detailed assays of the growth plates of the mutant mice revealed that the observed perturbations of the columnar organization of chondrocytes were associated with ER stress, abnormal architecture of collagenous matrix, unusual organization of primary cilia, atypical cell polarization, and reduced proliferation of chondrocytes harboring the R992C mutant collagen II molecules. Here, switching off the expression of the mutant transgene through the entire prenatal and postnatal experimental periods provided a meaningful control group in which the development of the pathological effects of the R992C substitution in collagen II was completely prevented. In future studies, switching off the expression of the mutant transgene at various stages of the prenatal and the postnatal development will define the ability of altered skeletal tissues developed in the presence of mutant molecules to regress pathological changes. Such information will be critical for predicting the efficacy of potential gene or cell therapies targeting skeletal diseases caused by mutations in collagen genes. ${ }^{15}$

\section{Material and Methods}

\section{Mutation Nomenclature}

The R992C (p.R1192C) amino acid substitution is named according to the literature, with amino acid residues numbered from the first glycine of the collagen triple helix.

\section{Mouse Model for Conditional Expression of the WT and Mutant Procollagen II Variants}

All mice received humane care according to the guidelines in the Guide for the Care and Use of Laboratory Animals. ${ }^{23}$ Procedures performed on animals were approved by the Thomas Jefferson University's Institutional Animal Care and Use Committee.

The following elements were used to generate a model for the conditional expression of transgenes: i) DNA constructs encoding the WT and the R992C pro- $\alpha 1$ (II) chains that include the Tet-controllable promoter; ii) tetracycline transactivator (tTA), a protein that mediates the Tetdependent inactivation of the promoter; and iii) a control system that facilitates the chondrocyte-specific expression of the procollagen II (Pro-II) variants. The first element was provided by using the DNA constructs encoding the pro$\alpha 1$ (II) chains whose expression is driven by the tetracycline response element-controlled cytomegalovirus (TRE-CMV) promoter, as described. ${ }^{21,22,24,25}$ In addition, the DNA constructs included a $3^{\prime}$-end cassette encoding green fluorescence protein (GFP), thereby enabling the direct observation of the expression patterns of the GFP-tagged WT and R992C Pro-II variants (ProGFP) in skeletal tissues, as described. ${ }^{21,22,24-27}$ The ProGFP chimeric construct was designed in such a way that on its secretion into the 
extracellular space, its GFP component is naturally cleaved off by procollagen C-proteinase (PCP) together with the procollagen C-propeptide, as described. ${ }^{25}$ Note that in vivo, the C-propeptides are promptly cleaved during secretion of procollagen molecules. ${ }^{28}$ By contrast, in cell culture conditions, such cleavage is extremely slow because of the low PCP concentration, thereby leading to the accumulation of mainly intact procollagen molecules in cell culture media. ${ }^{29}$ The second requirement was accomplished by using mice, referred to as tTA mice, harboring the loxP-flanked $\beta$-geo transcriptional STOP cassette preventing transcription of the downstream sequence encoding tTA protein $(G t(R O S A)$ 26 Sor $^{\text {tm5 }}{ }^{(A C T B-t T A) L u o} / \mathrm{J}$; Stock\# 012266; The Jackson Laboratory, Bar Harbor, ME). ${ }^{30}$ A number of variants of tTAharboring mice were successfully used in Tet-regulated models for the expression of skeletal elements, thereby validating the utility of tTA to exert its biological functions in the environment of skeletal tissues. ${ }^{31-34}$ Finally, the chondrocyte-specific expression of the ProGFP constructs was assured by using mice, referred to as Col2a1-cre mice, expressing Cre recombinase under the control of the Col2al promoter (B6;SJL-Tg(Col2al-cre)1Bhr/J; Stock \#003554; The Jackson Laboratory). ${ }^{31-33,35-37}$

\section{Founder Mice}

Founder mice were generated in the Transgenic Mouse Facility of Thomas Jefferson University by random insertion of the DNA constructs encoding the WT or the R992C ProGFP variants. Unique sets of PCR primers targeting the $5^{\prime}$ region of the DNA constructs encoding the $\mathrm{N}$ terminus and the $3^{\prime}$ region encoding the $\mathrm{C}$ terminus of Pro-II variants were used to identify the transgene-positive mice (Table 1). Subsequently, the transgene-positive founders were crossed with nontransgenic mice (C57BL/6J; The Jackson Laboratory) to generate the $F_{1}$ offspring.

\section{Elimination of Mice with Leaky Expression of Transgenes}

Because the $\mathrm{F}_{1}$ transgene-positive mice lack tTA, an element needed to activate the TRE-CMV promoter, the expression of the ProGFP constructs is not expected. Still, unspecific expression may occur in any cell even in the absence of tTA because of the particular chromosomal environment at the transgene integration. ${ }^{38}$ Consequently, RT-PCR assays were used to eliminate mice with a leaky expression of the ProGFP constructs. In brief, the total RNA was isolated from the tail clips of the transgene-positive mice. Subsequently, RT-PCR was performed with a set of primers targeting unique $5^{\prime}$ and $3^{\prime}$ regions of specific DNA constructs (Table 1). In addition, control RT-PCR assays targeting mRNA for glyceraldehyde 3-phosphate dehydrogenase (GAPDH) were performed with all analyzed samples. The $F_{1}$ mice with leaky expression of the ProGFP constructs, detected by the presence of the RTPCR-positive bands, were excluded from further studies. Consequently, two lines harboring the $\mathrm{WT}^{\text {ProGFP }}$ and two lines harboring the R992C ${ }^{\text {ProGFP }}$ constructs were selected and evaluated.

\section{Assays of Transgene Copy Number}

Assays to determine the number of copies of the transgenes were performed by ACGT (Wheeling, IL) with the use of quantitative PCR. In brief, DNA was extracted from the transgenic and control mice. In addition, purified plasmids with DNA constructs for the WT and the R992C ProGFP variants were also used. Two sets of primers, one targeting the $5^{\prime}$-end and the second one targeting the $3^{\prime}$-end of a construct were used. Both the $5^{\prime}$-end and the $3^{\prime}$-end PCR targets and the beta actin-specific target were amplified from each test genomic DNA sample in triplicate, with the 7900HT Sequence Detection System (Applied Biosystems; Life Technologies, Grand Island, NY). Absolute copy numbers of analyzed targets in each sample were determined by comparing their threshold cycle values with the plasmid copy number standard curves generated, and reported as the average number of transgenic sequence copies per cell.

\section{Breeding Strategy}

The tTA and the Col2a1-cre mice were crossed and then the offspring was tested by PCR for the presence of the tTA and the Col2a1-cre transgenes (Table 1). Subsequently, the double heterozygotes were crossed with the selected heterozygous lines harboring the $\mathrm{WT}^{\text {ProGFP }}$ or the R992C $\mathrm{C}^{\text {ProGFP }}$ constructs.

Table 1 PCR Primers Used to Screen Transgenic Mice

\begin{tabular}{|c|c|c|}
\hline PCR target & Forward primer & Reverse primer \\
\hline ProGFP/N* & $5^{\prime}$-ACGCCATCCACGCTGTTTTGACC-3' & $5^{\prime}-\mathrm{AGCACCCGCCTCTCCCTTAGCA-3'}$ \\
\hline $\operatorname{ProGFP} / C^{*}$ & $5^{\prime}$-CGGGCAGAGGGCAATAGCAGGTT-3' & $5^{\prime}$-GTCGCCGATGGGGGTGTTCT-3' \\
\hline tTA & $5^{\prime}$-СTCTGCTGCCTCCTGGCTTCT- $3^{\prime \dagger}$ & $\begin{array}{l}5^{\prime}-\text { CGAGGCGGATCACAAGCAATA }-3^{\prime \ddagger} \\
5^{\prime}-\text { TCAATGGGCGGGGGTCGTT }-3^{\prime \S}\end{array}$ \\
\hline
\end{tabular}

*ProGFP/N, ProGFP/C: PCR primer sets that target DNA regions encoding the $\mathrm{N}$-terminal and the C-terminal domains of the ProGFP construct, respectively.

${ }^{\dagger}$ A forward primer recognizing the WT and the transgene DNA target.

${ }^{\ddagger} \mathrm{A}$ reverse primer targeting a region of the WT mouse DNA.

${ }^{\S} \mathrm{A}$ reverse primer targeting a region of the tTA transgene. 
The identical breeding strategy was used for experiments with a group in which the expression of the $\mathrm{WT}^{\text {ProGFP }}$ or the R992C ${ }^{\text {ProGFP }}$ constructs was switched off. In these experiments, the breeders were provided with $1.0 \mathrm{mg} / \mathrm{mL}$ Dox supplied in drinking water supplemented with $2 \%$ sucrose. Dox was supplied during the entire pregnancy and was continued postnatally up to 10 weeks until mice were sacrificed. Based on published literature, the Dox dosage, administration route, and duration of treatment used here are in the safe range that is not associated with any apparent adverse effects. ${ }^{32,33,39,40}$

\section{Analysis of Triple Transgenes}

Offspring generated via the described breeding strategy were analyzed by PCR for the presence of the tTA, the Col2a1-cre, and the ProGFP constructs. The Col2a1cre-specific and the ProGFP-specific PCR assays were performed with specific forward and reverse primers (Table 1). The tTA-specific assays were performed with a primer set consisting of one forward and two reverse primers, according to The Jackson Laboratory protocol (Table 1). In this configuration, the slow-migrating PCR product corresponded to the native genomic sequence, whereas the fast-migrating band represented the amplified tTA-specific target. In addition, following the skin removal, portions of the tail clippings from the analyzed mice were observed directly with a stereo fluorescence microscope (MVX10; Olympus, Center Valley, PA) for the presence of GFP-positive signals.

In the subsequent paragraphs, the triple-transgene mice harboring the WT ${ }^{\text {ProGFP }}$ or the R992 ${ }^{\text {ProGFP }}$ construct together with tTA and the Col2a1-cre transgenes are described as $\mathrm{WT}^{\text {ProGFP(+) }}$ or R992 $\mathrm{C}^{\text {ProGFP(+) }}$, respectively, whereas those negative for one, two, or three required transgenes are defined as the $\mathrm{WT}^{\text {ProGFP(-) }}$ or the $\mathrm{R} 992 \mathrm{C}^{\operatorname{ProGFP}(-)}$. Corresponding mice maintained in the presence of Dox are identified as: ${ }^{D o x} \mathrm{WT}^{\text {ProGFP(+) }}{ }^{\text {Dox }} \mathrm{R} 992 \mathrm{C}^{\operatorname{ProGFP}(+)}{ }^{{ }^{D o x}} \mathrm{WT}^{\operatorname{ProGFP}(-)}$, and ${ }^{\text {Dox }} \mathrm{R} 992 \mathrm{C}^{\mathrm{ProGFP}(-)}$, respectively.

\section{Isolation of Chondrocytes from Articular Cartilage}

Femora and tibiae were dissected from 10-week-old mice expressing the ProGFP variants maintained constantly in the absence of Dox. Using a stereo microscope, slices of articular cartilage were dissected from the femoral heads, condyles, and the tibia condyles. Subsequently, the cartilage samples were digested with collagenase (Worthington Biochemical Corp., Lakewood, NJ) added to a final concentration of $1000 \mathrm{U} / \mathrm{mL}$. The digested samples were washed with Dulbecco's modified Eagle's medium supplemented with $10 \%$ fetal bovine serum. Next, the chondrocytes released from the cartilage tissue were seeded in the same cell culture medium into the wells of a cell culture dish and then visualized by fluorescence microscopy for the presence of a GFP-positive signal. In addition, a separate set of these cells was maintained in the presence of Dox added to culture at $1 \mu \mathrm{g} / \mathrm{mL}$ to demonstrate the ability of the designed system to switch off the expression of the ProGFP constructs, as described. ${ }^{21,22,24,25}$

\section{Analysis of ProGFP Secreted from Chondrocytes}

Analyses of the total pool of Pro-II secreted from chondrocytes and its ProGFP fraction were done, as described. ${ }^{21,22,24,25}$ In brief, chondrocytes were cultured in Dulbecco's modified Eagle's medium supplemented with $10 \%$ fetal bovine serum and $40 \mu \mathrm{g} / \mathrm{mL}$ L-ascorbic acid phosphate magnesium salt $n$-hydrate (Wako Pure Chemical Co., Osaka, Japan). Western blot assays were used to detect the presence of Pro-II in cell culture media. In these qualitative assays, proteins were precipitated from cell culture media with 5\% polyethylene glycol (Sigma-Aldrich), and then the precipitated proteins were separated electrophoretically, as described. ${ }^{41}$ Subsequently, the Pro-II variants were probed with the use of the anti-collagen II antibody (EMD Millipore, Billerica, MA) recognizing epitopes in the endogenous and the exogenous collagen II molecules and with the anti-GFP antibody (Santa Cruz Biotechnology, Dallas, TX) that uniquely recognizes the GFP tag of the exogenous ProGFP constructs, as described. ${ }^{21,22,25}$

In addition to secretion of Pro-II, the presence of Cre in isolated chondrocytes was analyzed in cell lysates. In brief, proteins present in the lysates from chondrocytes isolated from mice that, based on PCR assays, were declared positive or negative for expression of Cre were analyzed by Western blot assays. In these assays, the anti-Cre antibody (Abcam, Cambridge, MA) was used to detect the presence of Cre, whereas the anti-GAPDH antibody (Santa Cruz Biotechnology) was used to detect GAPDH, which served as an internal control.

\section{Gross Morphology of Skeletal Tissues}

Transgenic mice were sacrificed at 6-week, 10-week, or 6-month time points. The overall morphologies of 6-weekold and 10-week-old mice skeletons were analyzed by X-ray imaging and whole skeleton staining with alizarin red and alcian blue. The gross morphology of 6-month-old mice was evaluated by direct observation of sacrificed, unprocessed animals.

\section{Morphometric Assays}

The skeletal indices of the L4 vertebrae, femora, tibiae, and skulls dissected from mice whose skeletons were stained with alizarin red and alcian blue were measured with a digital caliper to $0.01 \mathrm{~mm}$ (Absolute Digimatic Caliper; Mitutoyo Corporation, Kawasaki-shi, Japan). Here, we present measurements from 10-week-old mice, an age group whose skeletal growth and maturation are still ongoing, but the rates of these processes are relatively low. ${ }^{42-45}$ The following 
measurements were recorded: i) for the L4 vertebrae: the vertebral height and the upper and the lower vertebral widths; ii) for the femora: the femoral length, the condylar, and the midshaft widths; iii) for the tibiae: the tibia length and the condylar, the midshaft, and the malleolar widths; and iv) for the skulls: the length, measured from the tip of the nasal bone to the back of the occipital bone, the width, measured at the widest point of the parietal bone, and the inner canthal distances. Subsequently, the length/mean-of-widths ratios were calculated to compare the shapes of the analyzed skeletal elements. Specifically, in comparing mutant mice with the relevant control group, a relatively small ratio was indicative of a disproportionately shorter bone. Comparisons were done between the following groups: i) $\mathrm{WT}^{\text {ProGFP(+) }}(n=3$; all males) and $\mathrm{WT}^{\text {ProGFP(-) }}(n=3$; all males $)$; ii)

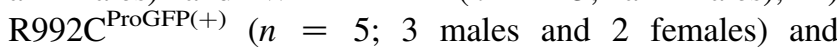
$\mathrm{R} 992 \mathrm{C}^{\text {ProGFP(-) }}(n=5 ; 3$ males and 2 females $)$; iii) ${ }^{\text {Dox }} \mathrm{WT}^{\text {ProGFP(+) }}(n=5 ; 1$ male and 4 females $)$ and ${ }^{\text {Dox }} \mathrm{WT}^{\text {ProGFP(-) }}(n=5 ; 1$ male, 4 females $)$; and iv $)$ ${ }^{\text {Dox }} \mathrm{R} 992 \mathrm{C}^{\text {ProGfP(+) }}(n=3 ; 1$ male, 2 females $)$ and ${ }^{\text {Dox }} \mathrm{R} 992 \mathrm{C}^{\text {ProGfP(-) }}(n=3 ; 1$ male, 2 females $)$. Note that although a group could include both sexes, each ProGFP $(+) / \operatorname{ProGFP}(-)$ pair of mice belonging to groups being compared was formed by littermates of the same sex. Because comparisons were done between the above groups that included pairs of sex-matched littermates, skewing of the final results was minimized.

\section{Histology of Skeletal Tissues}

For histological analyses, fore and hind limbs were collected. Subsequently, corresponding fore and hind paws were separated from the limbs and then processed independently. In addition, lumbar vertebrae were also collected. Samples were fixed in a $4 \%$ solution of paraformaldehyde and then decalcified in a solution of $14 \%$ EDTA $(\mathrm{pH}=7.1)$ for 2 weeks. To minimize quenching of the GFP-specific fluorescence, decalcification was done in tubes wrapped in aluminum foil. The decalcified samples were embedded in paraffin or in the optimal cutting temperature (Sakura Finetek USA, Torrance, CA) compound for direct visualization of GFP in processed frozen tissues. The paraffin-embedded samples were stained with alcian blue and $H \& E$ to visualize the general morphology and the cellularity of the analyzed specimens. In addition, samples were stained with Sirius red (Polysciences, Warrington, PA) followed by analyses of birefringent collagen fibrillar deposits with the use of a polarizing microscope (Eclipse LV100POL; Nikon, Melville, NY).

The optimal cutting temperature compound-embedded samples were cut into $20-\mu \mathrm{m}$ slices and then stained with DAPI to visualize the nuclei. Subsequently, these samples were observed with the use of a fluorescent microscope (Eclipse E600; Nikon) to analyze the pattern of distribution of the GFP-positive cells. In addition to fluorescence images, selected unstained samples were also visualized by differential interference contrast microscopy to highlight detailed morphological features of analyzed regions.

\section{Immunostaining of the Growth Plates}

Tissue slices (3- to 5- $\mu \mathrm{m}$ thick) of paraffin-embedded knee joints were deposited on glass slides (ColorfrostPlus; Thermo Fisher Scientific, Waltham, MA) and then processed for immunohistology. The following antigens were analyzed: i) collagen II, a structural protein of cartilage; ii) collagen X, a structural element of the hypertrophic zone; iii) binding immunoglobulin protein $(\mathrm{BiP})$, a chaperon protein whose increased amount serves as an indicator of ER stress; iv) Golgi matrix protein (GM-130), a Golgispecific protein; v) acetylated tubulin, used to detect primary cilia; and vi) proliferating cell nuclear antigen (PCNA), used as a marker of the division of chondrocytes. ${ }^{46,47}$

In all immunostaining protocols, tissue slices were stabilized by baking them for 30 minutes at $60^{\circ} \mathrm{C}$. To detect collagen II and collagen $\mathrm{X}$, the samples were treated for 30 minutes at room temperature with $0.1 \mathrm{mg} / \mathrm{mL}$ chondroitinase ABC (Sigma-Aldrich, St. Louis, MO) solubilized in $50 \mathrm{mmol} / \mathrm{L}$ Tris, $60 \mathrm{mmol} / \mathrm{L} \mathrm{CH} \mathrm{CH}_{3} \mathrm{COONa}(\mathrm{pH}=8.0)$, followed by treatment with $0.1 \mathrm{mg} / \mathrm{mL}$ pepsin (SigmaAldrich) solubilized in $50 \mathrm{mmol} / \mathrm{L} \mathrm{CH} \mathrm{CH}_{3} \mathrm{COOH}$. Subsequently, the samples were treated with the anti-collagen II antibody (dilution 1:500; Acris Antibodies, San Diego, CA) or the anti-collagen $\mathrm{X}$ antibody (dilution 1:500; Bioss, Woburn, MA). Finally, collagen II was visualized with the use of the anti-mouse biotinylated antibody (M.O.M. Kit; Vector laboratories, Burlingame, CA) and the streptavidinconjugated Alexa Fluor 594 (Molecular Probes, Life Technologies). Collagen $\mathrm{X}$ was detected by using biotinylated anti-rabbit IgG antibody (Vector Laboratories), horseradish peroxidase, and the NovaRED horseradish peroxidase substrate (Vector Laboratories). For detection of $\mathrm{BiP}$ and GM-130, the antigen-retrieval process included 2-hour treatment with citric buffer at $70^{\circ} \mathrm{C}$. Following the blocking step, either the anti-BiP antibody (1:200; Thermo Fisher Scientific) or the anti-GM-130 antibody (dilution 1:200; Abcam) was used to detect indicated antigens. Next, BiP and GM130 were detected with the anti-rabbit IgG secondary antibody conjugated to Alexa Fluor 594 (Molecular Probes; Life Technologies). For immunostaining of PCNA, the tissue was digested with $0.1 \mathrm{mg} / \mathrm{mL}$ chondroitinase $\mathrm{ABC}$ followed by treatment with the anti-PCNA antibody (dilution 1:200; Thermo Fisher Scientific). Subsequently, the PCNA-antibody complex was visualized with the use of the biotinylated anti-mouse $\mathrm{IgG}$ secondary antibody (M.O.M. Kit; Vector Laboratories) and the streptavidin-conjugated Alexa Fluor 594. To immunostain primary cilia, the samples were pretreated with $0.1 \mathrm{mg} / \mathrm{mL}$ chondroitinase $\mathrm{ABC}$ and then exposed to the anti-acetylated tubulin antibody (dilution 1:300; Sigma-Aldrich). Finally, acetylated tubulin was detected with the use of the biotinylated anti-mouse IgG secondary antibody (M.O.M. Kit; 
Vector Laboratories) and the streptavidin-conjugated Alexa Fluor 594. In all samples stained with Alexa Fluor 594, the nuclei were dyed with DAPI, whereas the samples stained with NovaRED were counterstained with methyl green (Vector Laboratories). The analyzed samples represented multiple histological sections of the analyzed specimens.

A fluorescence microscope (Eclipse E600; Nikon) equipped with a digital camera (DS-Qi1Mc; Nikon) was used to document samples labeled with a fluorophore. Microscopic images were processed with the use of the NIS Elements software version 3.22.14 (Nikon). To document primary cilia, a sequence of images of consecutive focal planes along the Z-axes of the analyzed areas was collected. Subsequently, these sequences were processed with the Extended Depth Focus module of the NIS Elements software (Nikon) to fully use in-focus information of the analyzed region of interest.

Measurements of the length of primary cilia were done with the use of the NIS-Elements software. A minimum of three mice per group were used, and then five tissue sections were analyzed for each mouse. Results were presented as means \pm SD. The statistical significance of the observed differences between the lengths of measured cilia seen in growth plates of the $\mathrm{WT}^{\operatorname{ProGFP}(+)}$ control and the $\mathrm{R} 92 \mathrm{C}^{\mathrm{ProGFP}(+)}$ mice was evaluated with the $t$-test (GraphPad Prism software version 6.05, La Jolla, CA).

\section{Proliferation of Chondrocytes}

The percentage of the PCNA-positive chondrocytes was determined by analyzing images of the growth plates of newborn and 10-week-old mice. In brief, using the NISElements software, the regions of interest corresponding to the growth plate areas were assigned. Subsequently, the PCNApositive and the DAPI-positive cells were counted in these areas. For each analyzed group, the percentages of the PCNApositive cells from a minimum of three independent samples were calculated. A minimum of five sections were prepared for each analyzed mouse. The average number of analyzed cells readily identifiable in defined regions of interest was approximately 150 . Results were presented as means \pm SD. The statistical significance of the observed differences between the percentages of the PCNA-positive cells seen in growth plates of the $\mathrm{WT}^{\mathrm{ProGFP}(+)}$ control and the R992 $\mathrm{C}^{\operatorname{ProGFP}(+)}$ mice or between corresponding values calculated for the ${ }^{D o x} \mathrm{WT}^{\text {ProGFP }(+)}$ control and the ${ }^{\text {Dox }} \mathrm{R} 992 \mathrm{C}^{\text {ProGFP }(+)}$ mice was evaluated with the $t$-test (GraphPad Prism Software).

\section{Results}

Transgenic Mice Harboring the $\mathrm{WT}^{\text {ProGFP }}$ or the R992C ProGFP Constructs

Ten founders expressing the $\mathrm{WT}^{\text {ProGFP }}$ construct and six founders harboring the R992C $C^{\text {ProGFP }}$ construct were selected by PCR. Next, the $F_{1}$ mice with leaky expression of the transgenes were eliminated from subsequent studies (Figure 1A). Finally, two lines harboring the $\mathrm{WT}^{\text {ProGFP }}$ construct and two lines harboring the R992C ${ }^{\text {ProGFP }}$ construct with no apparent signs of leaky expression of the transgenes were selected. The presence of PCR products representing Gapdh internal control in all analyzed samples (not shown) validated the transgene-specific assays.

\section{Copy Number}

The estimated number of transgene copies for two selected lines harboring the WT ${ }^{\text {ProGFP }}$ transgene was 2 and 8, respectively. Analogical values for two selected lines harboring the R992C ${ }^{\text {ProGFP }}$ transgene were 2 and 3, respectively. Initial morphological analyses of mice with different copy numbers within WT $^{\text {ProGFP }}$ or R992C ${ }^{\text {ProGFP }}$ transgenic lines did not show any major differences in the analyzed parameters. In our study, we focused on analyzing the lines that carried two copies of the transgene.

\section{Tet-Regulated Expression of the Transgene}

Selected transgenic mice were crossed with double heterozygotes expressing the tTA and the Col2a1-cre transgenes. Subsequent PCR assays identified the triple-transgenic $\mathrm{WT}^{\operatorname{ProGFP}(+)}$ and $\mathrm{R}^{2} 92 \mathrm{C}^{\operatorname{ProGFP}(+)}$ mice harboring the ProGFP construct, the tTA, and the Col2a1-cre DNA constructs (Figure 1B). For 378 transgenic mice screened to date, $55(14.6 \%)$ harbored all three transgenes, a percentage closely reflecting the value of $12.5 \%$ theoretically predicted as the percentage of the triple-transgene offspring generated with the breeding protocol used here.

In all $\mathrm{WT}^{\text {ProGFP(+) }}$ and $\mathrm{R} 992 \mathrm{C}^{\text {ProGFP(+) }}$ mice maintained in the absence of Dox, the GFP-positive cells were clearly apparent in tail clippings observed directly under a stereo fluorescence microscope (Figure 1C). By contrast, no GFPpositive signals were seen in the $\operatorname{WT}^{\operatorname{ProGFP}(-)}$ or R992 ${ }^{\text {ProGFP(-) }}$ mice harboring only a combination of any two transgenes of the required three (not shown). In the ${ }^{\text {Dox }} \mathrm{WT}^{\text {ProGFP(+) }}$ (not shown) and the ${ }^{\text {Dox }}$ R992C ${ }^{\text {ProGFP(+) }}$ mice, no GFP-positive signals were observed (Figure 2C).

\section{Tissue-Specific Expression of the ProGFP Variants}

Direct microscopic assays of frozen skeletal tissues from the newborn ProGFP $(+)$ mice indicated tissue-specific expression of the ProGFP constructs (Figure 2, A and B, and Figure 3). Analyses of the limbs of the newborn mice indicated that the GFP-positive signals were primarily observed in the articular cartilage (Figure 3, A-C, E, and F) and in the growth plates (Figure 3, B, C, E, and F). Moreover, observations of vertebrae demonstrated that the majority of the GFP-positive cells were located in the area of vertebral endplates and growth plates (Figure 3D). No GFPpositive signals were observed in cells from surrounding tissues such as muscle and skin (Figure 3, C, E, and F). 


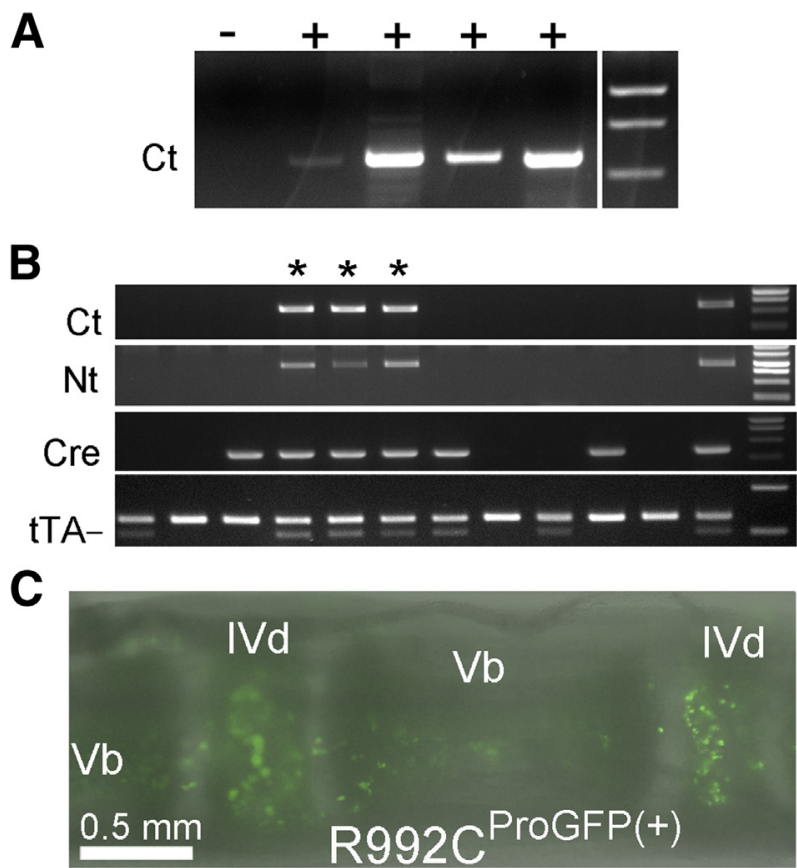

Figure 1 Genotyping the transgenic mice. A: A representative image of an agarose gel depicting products of RT-PCR with the use of templates isolated from the $F_{1}$ mice harboring a transgene encoding the ProGFP chimera. Positive $(+)$ bands indicate leaky expression of a transgene in the $F_{1}$ mice that lack transgenes for tTA and for Col2a1-cre. Only mice with no apparent expression of a transgene (-) were used for the described study. B: PCR scanning for the presence of triple-transgene mice (asterisks) harboring constructs for ProGFP, tTA, and Col2a1-cre; note that the tTAspecific PCR products amplified with the use of a set of three primers include both a product encompassing an endogenous DNA template (upper band) and a tTA-specific product (lower band). C: A representative image of a tail fragment from the $\mathrm{R}_{9} 2 \mathrm{C}^{\mathrm{ProGFP}(+)}$ mice observed under a stereo fluorescence microscope. Note that the presented image consists of overlaid images observed in visible light and in a fluorescence mode. Although the skin portion of the observed tail fragment was removed, the subdermal soft tissues were still present in the analyzed specimen, thereby obstructing the more detailed view of the tail fragment. Still, vertebral bodies (Vb) and intervertebral disk (IVd) areas were readily distinguishable. Cre, PCR product corresponding to the DNA region encoding Col2a1-cre; $\mathrm{Ct}$, amplified DNA fragment encoding the $\mathrm{C}$ terminus of the ProGFP construct; $\mathrm{Nt}$, amplified DNA fragment encoding the $\mathrm{N}$ terminus of the ProGFP construct; tTA, PCR product corresponding to the specific DNA region encoding tTA.

Because observations of the GFP-positive cells were done on relatively thick samples, the apparent intensities of GFPpositive signals were not uniform. Consequently, to avoid oversaturation of the presented images, only the most intense GFP-positive signals are clearly apparent at low magnification. Furthermore, the apparent lack of uniformity of the strength of the GFP-positive signals could be also a result of uneven signal quenching during the 2-week decalcification process.

\section{Chondrocyte Expression of the ProGFP Variants}

Continuous expression of the ProGFP variants (Figure 4, $\mathrm{A}$ and $\mathrm{B}$ ) and the proper functioning of the Tet-off system in chondrocytes isolated from 10-week-old mice were confirmed by switching off the production of the ProGFP molecules in cells cultured in the presence of $1 \mu \mathrm{g} / \mathrm{mL}$ Dox (Figure 4C). Complete inhibition of the production of the ProGFP molecules was evident in the microscopic and the electrophoretic assays after a 48-hour treatment of cells with Dox (Figure 4, C and D). Constant expression of Cre detected in lysates from chondrocytes obtained from 10-week-old ProGFP $(+)$ mice further indicates the long-term stability of the used expression system (Figure 4E).

Expression of the ProGFP constructs and their secretion to the extracellular space were confirmed microscopically and biochemically (Figure 4). ${ }^{21,22}$ As expected, the ProGFPpositive bands were seen only in the $\operatorname{ProGFP}(+)$ mice maintained in the absence of Dox (Figure 4D). ${ }^{21,22}$ By contrast, collagen II-positive bands, representing the endogenous or the exogenous collagen II molecules, were present in conditioned cell culture media derived from the chondrocytes isolated from the ProGFP $(+)$ mice and from their ProGFP(-) littermates (Figure 4D). Consistent with the earlier studies, collagen II-positive bands that migrated faster than those corresponding to intact Pro-II chains represented products of enzymatic degradation. ${ }^{21,48,49}$

\section{Gross Morphology of Skeleton of Mutant Mice Harboring the R992C ${ }^{\text {ProGFP }}$ Transgene}

Examination of skeletons of the 6-week-old (not shown), 10-week-old R992C ${ }^{\operatorname{ProGFP}(+)}$, and the R992C ${ }^{\text {ProGFP(-) }}$ littermates showed shortening of trunk and long bones in the $\mathrm{R} 992 \mathrm{C}^{\text {ProGFP(+) }}$ mice (Figure 5, A and B). In the group of 6-month-old mice, the size of the R992 $\mathrm{C}^{\operatorname{ProGFP}(+)}$ mice was noticeably smaller than in the group of the sex-matched R992 $\mathrm{C}^{\text {ProGFP(-) }}$ littermates (Figure 5C). Accordingly, the average mass of $24.2 \mathrm{~g}$ for the $\mathrm{R} 992 \mathrm{C}^{\operatorname{ProGFP}(+)}$ mice was significantly reduced by $30 \%(P=0.02)$ when compared to the $\mathrm{R} 992 \mathrm{C}^{\text {ProGFP(-) }}$ mice, whose average mass was $33.7 \mathrm{~g}$. By contrast, no statistically significant differences $(P=0.2)$

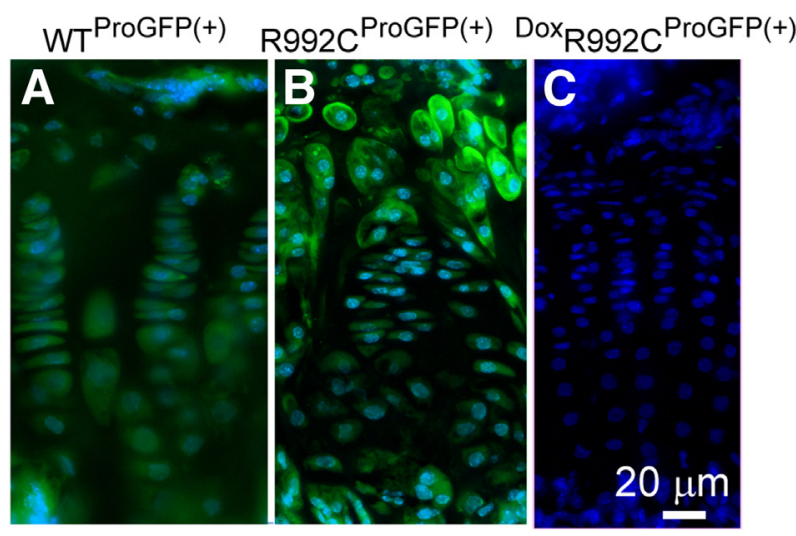

Figure 2 Visualization of chondrocytes present in growth plates of 10 week-old WT ${ }^{\text {ProGFP(+) }}(\mathbf{A})$, R992C $C^{\text {ProGFP(+) }}(\mathbf{B})$, and ${ }^{\text {Dox R992C ProGFP(+) }}(\mathbf{C})$ transgenic mice. 


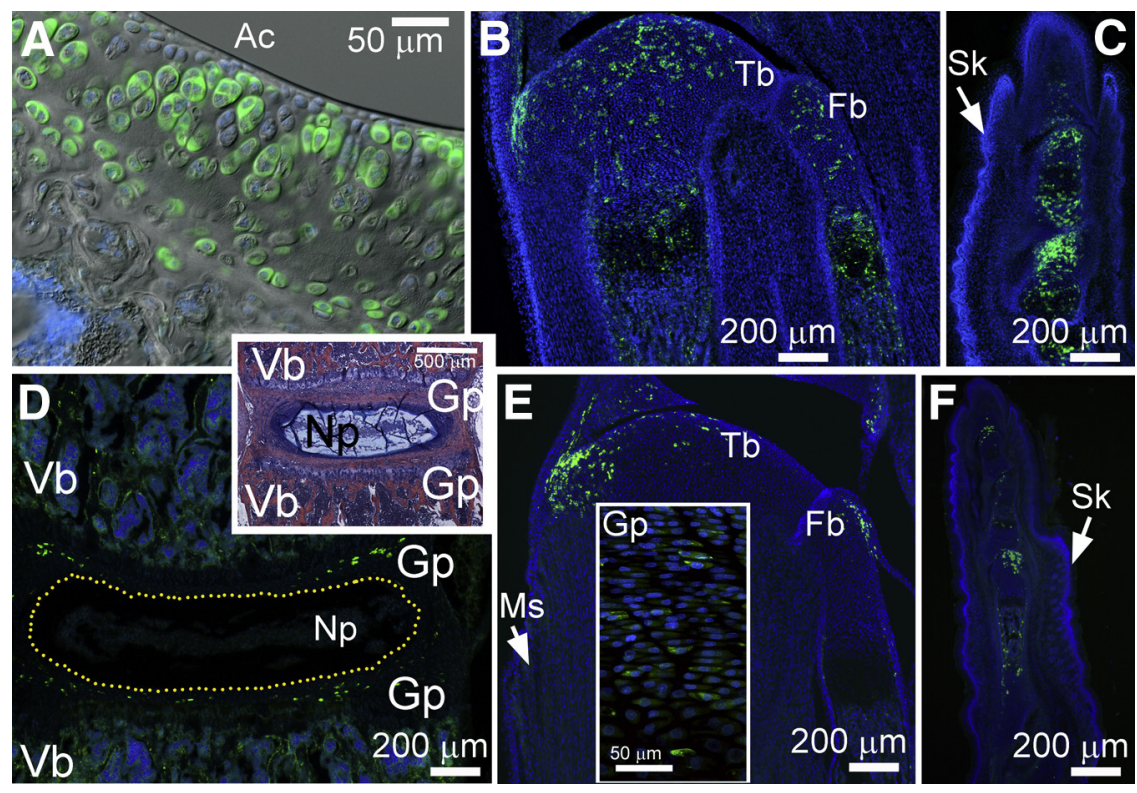

Figure 3 Localization of GFP-positive cells. A: An image depicting tibial articular cartilage of 6-week-old mice expressing the ProGFP construct. This image comprises overlaid differential interference contrast and fluorescence images of the selected region. B and C: Tibia/fibula and a paw of the $\mathrm{R}_{9} \mathrm{C}^{\text {ProGFP(+) }}$ mouse. D: An intervertebral region of a 10-week-old transgenic mouse expressing the ProGFP construct; a nucleus pulposus area is delineated with a dotted line. An inset included in $\mathbf{D}$ indicates $\mathrm{H} \& \mathrm{E}$ staining of the intervertebral region. $\mathbf{E}$ and $\mathbf{F}$ : Tibia/fibula and a paw of the $\mathrm{WT}^{\mathrm{ProGFP}(+)}$ newborn mouse. The inset depicts chondrocytes present in the growth plate. Arrows indicate noncartilaginous tissues in which the GFP-positive cells are absent (C, E, and $\mathbf{F})$. Fb, fibula; Gp, growth plate; Ms, muscle; Np, nucleus pulposus; Sk, skin; Tb, tibia; Vb, vertebral body.

were observed between the $\mathrm{WT}^{\operatorname{ProGFP}(-)}$ and the $\mathrm{WT}^{\operatorname{ProGFP}(+)}$ mice, whose average masses were $36.7 \mathrm{~g}$ and $32.7 \mathrm{~g}$, respectively (mice not shown).

Comparison of skeletal indices associated with femora, tibiae, and lumbar vertebrae of the R992 $\mathrm{C}^{\text {ProGFP(-) }}$ mice and the $\mathrm{R}_{992 \mathrm{C}^{\text {ProGFP(+) }}}$ littermates indicated statistically significant differences in all measured parameters (Figure 6A). Specifically, analyses of the length/width ratios in the measured bones showed that the femora, tibiae, and vertebrae of the $\mathrm{R} 992 \mathrm{C}^{\mathrm{ProGFP}(+)}$ mice were relatively shorter and wider when compared to the $\mathrm{R} 992 \mathrm{C}^{\text {ProGFP(-) }}$ littermates.
Similarly, the R992C ${ }^{\text {ProGFP(+) }}$ mice had shortened heads as evident by a significantly reduced length/width ratio of the analyzed skulls. By contrast, no statistically significant differences were seen in the analyzed indices describing the measured bones in the $\mathrm{WT}^{\mathrm{ProGFP}(+)}$ and the $\mathrm{WT}^{\mathrm{ProGFP}(-)}$ littermates (Figure 6A).

In a group of 10-week-old mice maintained in the presence of Dox, no statistical differences were observed between the indices calculated for the analyzed bones derived from the ${ }^{\text {Dox }} \mathrm{R} 992 \mathrm{C}^{\text {ProGFP(+) }}$ and the ${ }^{\text {Dox }} \mathrm{R} 992 \mathrm{C}^{\text {ProGFP(-) }}$ littermates (Figure 6B). Similarly, no statistical differences were
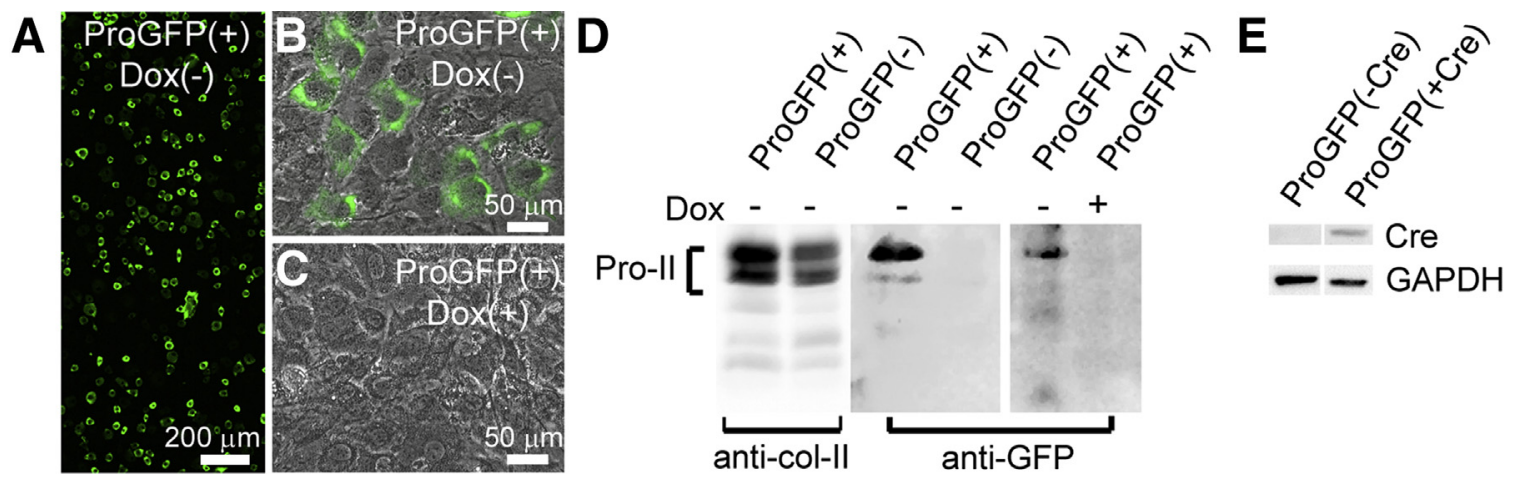

Figure 4 Tet-regulated expression of the ProGFP constructs. A: A general view of cultured articular chondrocytes isolated from 10-week-old ProGFP( + ) mice maintained in the absence of doxycycline (Dox) (-). B: A phase contrast/fluorescence image depicting a close view of chondrocytes expressing the ProGFP construct in the absence of Dox (-). C: Corresponding chondrocytes cultured in Tet-off conditions in the presence of Dox ( + ). D: Western blot assays of procollagen II (Pro-II) variants secreted by articular chondrocytes isolated from a transgenic mouse. Left panel shows results of assays of a total population of Pro-II secreted by chondrocytes isolated from the ProGFP $(+)$ mice and from their ProGFP( $(-)$ littermates. This population consists of endogenous and exogenous collagen II molecules secreted to the extracellular space. These chains were detected with the anti-collagen II antibody (anti-col-II) that recognizes common epitopes present in both endogenous and exogenous collagen II molecules. Multiple bands seen in this panel represent intact and processed Pro-II chains. Middle panel depicts Western blot analysis of the presence of ProGFP constructs in conditioned cell culture media of chondrocytes isolated from the ProGFP(+) mice and from their ProGFP( $(-)$ littermates. Right panel shows the result of assays of the ProGFP construct in culture media from ProGFP(+) chondrocytes cultured in the absence $(-)$ and in the presence $(+)$ of Dox. Protein bands seen in the middle and the right panels were detected with GFPspecific antibody. E: Western blot assays indicating the absence of cre in the ProGFP( $(-)$ mice and its presence in their ProGFP $(+)$ littermates. The presence of GAPDH in analyzed lysates is also indicated. 

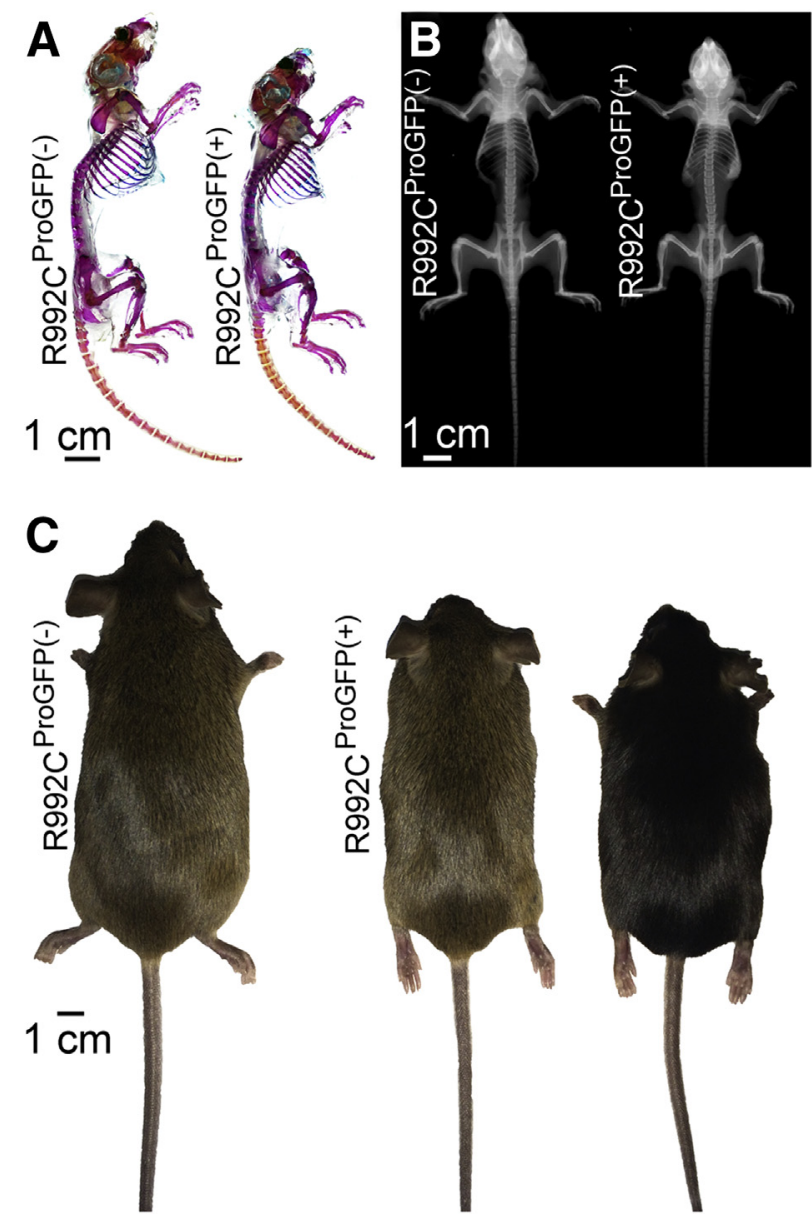

Figure 5 Gross morphology of skeletons of mice harboring the R992C collagen II mutation. A: Alcian blue and alizarin red staining of skeletons

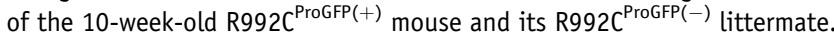
B: X-ray images of the R992 $\mathrm{C}^{\text {ProGFP(+) }}$ and the R992 $\mathrm{C}^{\text {ProGFP(-) }}$ mice. C: General morphologies of the 6-month-old R992 $C^{\text {ProGFP }(-)}$ and $\operatorname{Rg92}^{\text {ProGFP }(+)}$ littermates.

observed in the corresponding indices of bones derived from the ${ }^{\mathrm{Dox}} \mathrm{WT}^{\mathrm{ProGFP}(+)}$ and the ${ }^{\mathrm{Dox}} \mathrm{WT}^{\mathrm{ProGFP}(-)}$ littermates maintained in Tet-off conditions (Figure 6B).

\section{General Features of Growth Plate Morphology}

We analyzed selected morphological features of growth plates from the newborn, 2-week-old, 6-week-old, and 10 -week-old mice. Direct observations of the GFP-positive cells suggest excessive accumulation of the ProGFP collagen II chains in apparently dilated chondrocytes present in the growth plates of the R992 ${ }^{\operatorname{ProGFP}(+)}$ mice (Figure 2B). The presence of similarly dilated cells was observed neither in the $\mathrm{WT}^{\mathrm{ProGFP}(+)}$ nor in the ${ }^{\text {Dox }} \mathrm{R} 992 \mathrm{C}^{\text {ProGFP(+) }}$ mice maintained in Tet-off conditions (Figure 2, A and C).

Histological staining of the tibial growth plates of the $\mathrm{R} 992 \mathrm{C}^{\mathrm{ProGFP(+)}}$ mice showed alterations in the organization of chondrocytes. In contrast to chondrocytes seen in the growth plates of the 6-week (not shown) and the 10-weekold WT $^{\text {ProGFP(-) }}$ (Figure 7A), WT ${ }^{\text {ProGFP(+) }}$ (Figure 7B), and the R992C ${ }^{\text {ProGFP(-) }}$ (Figure 7 C) mice, the columnar organization of chondrocytes in the $\mathrm{R} 992 \mathrm{C}^{\operatorname{ProGFP}(+)}$ littermates was altered (Figure 7D). For instance, in the R992 $\mathrm{C}^{\text {ProGFP(+) }}$ mice, such alterations were indicated by the presence of disorganized columns whose continuity of the typical palisade-like arrangement was often interrupted by extended areas in which the chondrocytes were absent (Figure 7D). Switching off the expression of the R992C ProGFP in the ${ }^{\text {Dox }} \mathrm{R} 992 \mathrm{C}^{\text {ProGFP(+) }}$ mice maintained in Tetoff conditions resulted in developing growth plates in which chondrocytes were organized correctly (Figure $7 \mathrm{H}$ ). Growth plates from these mice had normal morphology comparable to that seen in the ${ }^{\operatorname{Dox}} \mathrm{R} 992 \mathrm{C}^{\operatorname{ProGFP}(-)}$ littermates (Figure $7 \mathrm{G}$ ) as well as their ${ }^{\text {Dox }} \mathrm{WT}^{\mathrm{ProGFP}(-)}$ and ${ }^{D o x} \mathrm{WT}^{\text {ProGFP( }(+)}$ counterparts maintained in Tet-off conditions (Figure 7, E and F).
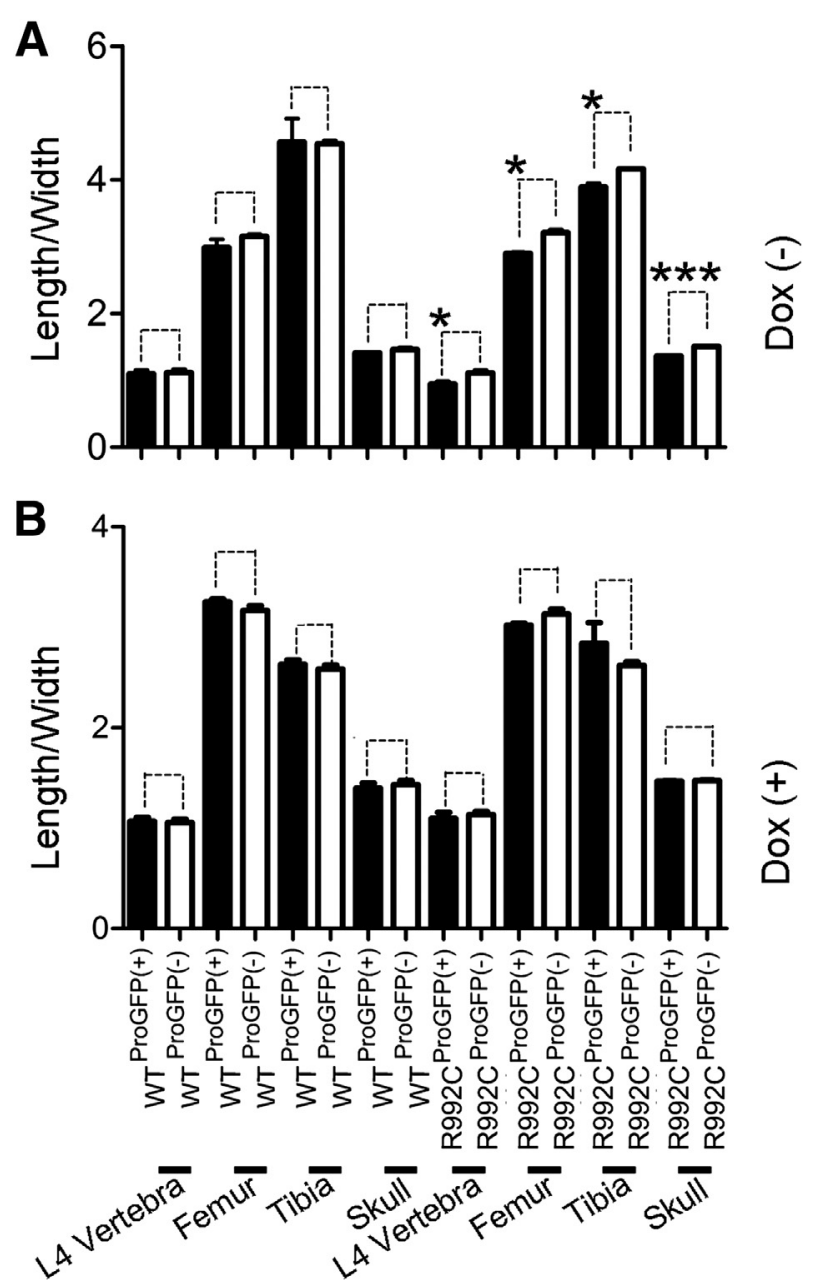

Figure 6 Graphic representation of differences between the length/ width ratios of vertebrae, femora, tibiae, and skulls of the 10-week-old mice maintained in the absence (A) or the presence (B) of doxycycline (Dox). The comparisons were done between the WT ${ }^{\operatorname{ProGFP}(-)}$ control group and matching $\mathrm{WT}^{\text {ProGFP(+) }}$ mice or between the R992 $\mathrm{C}^{\text {ProGFP(-) }}$ control group and matching $\mathrm{R} 92 \mathrm{C}^{\mathrm{ProGFP}(+)}$ mice. Dotted lines indicate specific pairs of groups whose morphometric parameters were compared. ${ }^{*} P<0.05,{ }^{* * *} P<0.001$ for the $\mathrm{R}_{922 C^{\text {ProGFP(+) }}}$ mice compared with the R992 ${ }^{\text {ProGFP(-) }}$ control. 


\section{Collagen II and Collagen X}

Collagen II-specific immunostaining demonstrated abundant deposition of this protein in the extracellular space of growth plates of the $\mathrm{WT}^{\mathrm{ProGFP}(+)}$ mice (Figure $8 \mathrm{~A}$ ). By contrast, in the growth plates of the $\mathrm{R} 992 \mathrm{C}^{\operatorname{ProGFP}(+)}$ mice, the extracellular content of collagen II was markedly reduced, whereas its increased intracellular accumulation was clearly apparent (Figure 8B). Similarly to the ${ }^{\text {Dox }} \mathrm{WT}^{\text {ProGFP(-) }}$ (Figure $8 \mathrm{C}$ ), ${ }^{\text {Dox }} \mathrm{WT}^{\text {ProGFP(+) }}$ (Figure 8D), and the ${ }^{\text {Dox }} \mathrm{R} 992 \mathrm{C}^{\text {ProGFP(-) }}$ (Figure $8 \mathrm{E}$ ) mice, in the ${ }^{\text {Dox }} \mathrm{R} 992 \mathrm{C}^{\text {ProGFP(+) }}$ mice (Figure $8 \mathrm{~F}$ ), in which expression of the mutant collagen II was turned off, the distribution pattern of collagen II was similar to that seen in the $\mathrm{WT}^{\text {ProGFP(+) }}$ (Figure 8A). Furthermore, analysis of Sirius red-stained deposits of collagen fibrils present in the growth plates of $\mathrm{WT}^{\operatorname{ProGFP}(+)}$ mice indicated their organized pattern of distribution in the longitudinal septa present between adjacent columns of chondrocytes (Figure $8 \mathrm{G}$ ). By contrast, the collagenous matrix present in the growth plates of the $\mathrm{R} 992 \mathrm{C}^{\text {ProGFP(+) }}{ }^{\text {mice lacked clear structural continuity, and }}$ the longitudinal septa were irregularly thickened (Figure 8H). In all analyzed groups, collagen fibril deposits seen in polarized light among the columns of chondrocytes were predominantly green. Because the color of Sirius red-stained collagen fibrils viewed in polarized light changes from green to yellow to orange to red with increasing fibril thickness, our observations indirectly indicate that the diameter of deposited fibrils was relatively small. ${ }^{50}$ Such a relatively small diameter is consistent with the diameters of native collagen II fibrils with an approximate thickness of $25 \mathrm{~nm} .{ }^{50}$

Assays of collagen $\mathrm{X}$ in 10-week-old mice indicate its expected distribution patterns in the hypertrophic zones of all analyzed groups (Figure 9). Still, in comparison to the corresponding area of controls (Figure 9, A, C, and D-F), in the $\mathrm{R} 992 \mathrm{C}^{\mathrm{ProGFP}(+)}$ mice, the area of distribution of collagen $\mathrm{X}$-rich matrix indicated by demarcation lines was irregular (Figure 9B).

\section{$\mathrm{BiP}$}

In contrast to the $\mathrm{WT}^{\mathrm{ProGFP}(-)}$ (Figure 10A), the $\mathrm{WT}^{\text {ProGFP(+) }}$ (Figure 10B), and the R992C $\mathrm{ProGPP}(-)^{\text {Pro }}$ (Figure 10C) controls in which the BiP-positive staining was at the background level, analyses of the growth plates of 2-week-old R992C ${ }^{\text {ProGFP(+) }}$ mice clearly show the BiPpositive staining of chondrocytes in the resting and proliferating zones (Figure 10D).

\section{Polarity of Chondrocytes}

The specific columnar arrangement of chondrocytes in the growth plates is a result of a series of movements and rotations of cells in the process that follows cell division. ${ }^{9}$ As a result of these processes, the columnar chondrocytes adopt a specific polarity. The polarities of cells, defined here by opposing Golgi apparatus and the nuclear sites, were well preserved in proliferating chondrocytes seen in the growth plates of the $\mathrm{WT}^{\text {ProGFP(+) }}$ mice (Figure 11C). By contrast, as indicated by the presence of Golgi-specific staining around the nuclei, the polarity of proliferating chondrocytes seen in the growth plates of the R992 $\mathrm{C}^{\text {ProGFP(+) }}$ mice was not clearly defined (Figure 11D). Similar differences in cell polarities were seen in the area of the periarticular chondrocytes (Figure 11, A and B). In this area, however, the organization of polarized cells in both analyzed groups lacked the columnar arrangement seen
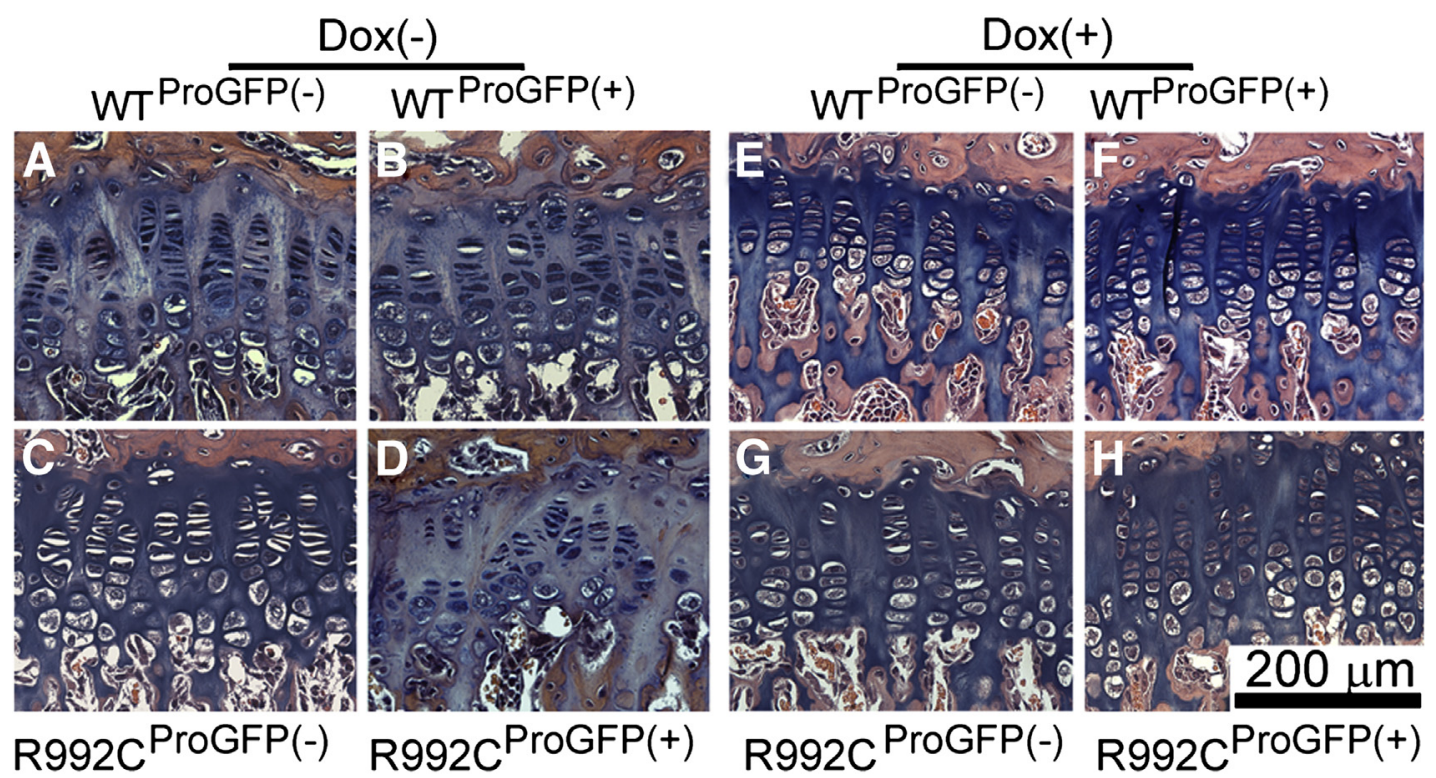

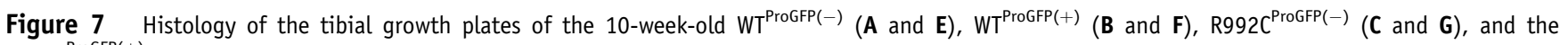
$\mathrm{R} 92 \mathrm{C}^{\text {ProGFP(+) }}(\mathbf{D}$ and $\mathbf{H})$ mice maintained in the absence $(\mathbf{A}-\mathbf{D})$ or the presence of Dox $(\mathbf{E}-\mathbf{H})$. 

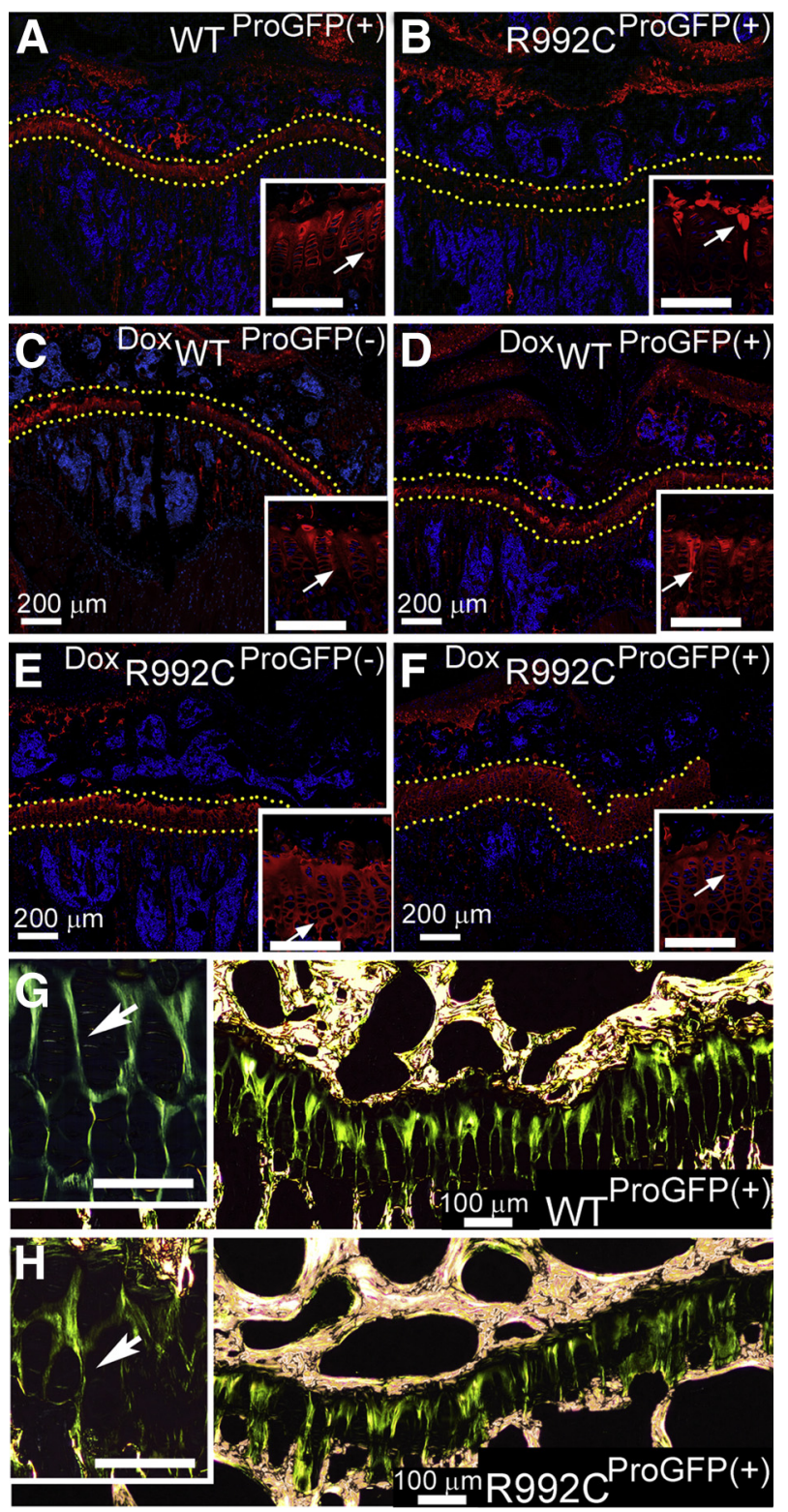

Figure 8 Analysis of collagen-rich deposits in growth plates of the 10-week-old mice. A-F: Collagen II-specific immunostaining (arrows) of tibial growth plates of the $\mathrm{WT}^{\text {ProGFP(+) }}, \mathrm{R} 92 \mathrm{C}^{\text {ProGFP(+) }}$, Dox WT $T^{\text {ProGFP(-) }}$,

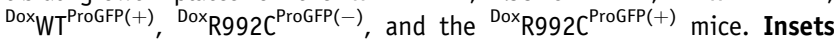
indicate enlarged detailed views of selected areas. Dotted lines delineate growth plate regions. G and H: Collagen-rich deposits visualized by collagen-specific staining with Sirius red. Arrows indicate collagen deposits present in septa separating columns of chondrocytes (insets). Orange/redcolored deposits represent collagen fibrils present in bone. Scale bars: 100 $\mu \mathrm{m}$ (insets).

in the proliferating zone. The Golgi apparatus-nucleus polarity in prehypertrophic and hypertrophic chondrocytes was maintained in neither of the analyzed groups of mice (Figure 11, E and F).

\section{Arrangement of Primary Cilia}

Parallel orientation of the primary cilia with respect to the longitudinal axis of bone is indicative of the proper organization of chondrocytes in growth plates. This parallel alignment was clearly apparent in chondrocytes of the newborn $\mathrm{WT}^{\text {ProGFP(+) }}$ mice (Figure 12A). In addition, in chondrocytes polarized along the Golgi apparatus-nucleus axis seen in the $\mathrm{WT}^{\mathrm{ProGFP}(+)}$ mice, primary cilia were clearly associated with the cellular site that corresponds to the localization of the Golgi apparatus (Figure 12A). By contrast, the parallel organization of cilia in corresponding growth plate regions of the newborn $\mathrm{R} 992 \mathrm{C}^{\mathrm{ProGFP}(+)}$ mice was not clearly established (Figure 12B).

In comparison to the newborn mice, the uniform pattern of primary cilia alignment in the growth plates of the 10-weekold mice was not clearly apparent (Figure 12, C-E). Still, when comparing the R992 $\mathrm{C}^{\operatorname{ProGFP}(+)}$ mice (Figure 12C) to the ${ }^{\text {Dox }} \mathrm{R} 992 \mathrm{C}^{\text {ProGfP(+)}}$ mice (Figure 12D), the cilia alignment in the latter group retained clear elements of the parallel arrangement seen in the $\mathrm{WT}^{\mathrm{ProGFP}(+)}$ control (Figure 12E).

The mean length of cilia present in growth plate chondrocytes seen in the $\mathrm{WT}^{\mathrm{ProGFP}(+)}$ mice was $2.1 \mu \mathrm{m}( \pm 0.08$ $\mathrm{SD}$ ), whereas the length of cilia observed in the corresponding areas of the $\mathrm{R} 992 \mathrm{C}^{\operatorname{ProGFP}(+)}$ mice was $1.5 \mu \mathrm{m}$ $( \pm 0.08 \mathrm{SD})$; the $t$-test indicated a statistically significant difference between the means $(P<0.0001)$.

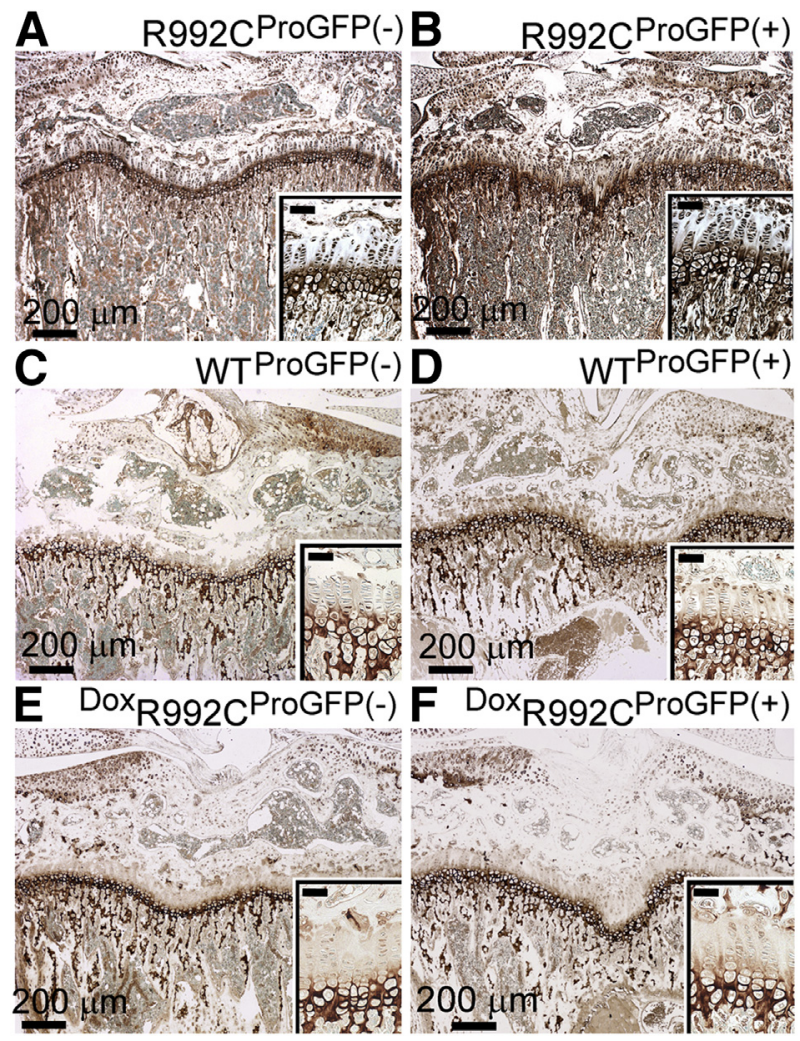

Figure 9 Immunostaining of collagen $\mathrm{X}$ in 10-week-old mice maintained in the absence (A-D) or the presence (E and $\mathbf{F}$ ) of doxycycline (Dox). Collagen $X$ deposits were visualized with the use of the anti-collagen $X$ antibody. In each depicted panel, the insets show a more detailed view of the extracellular matrix of the hypertrophic regions. Scale bars: $100 \mu \mathrm{m}$ (insets). 


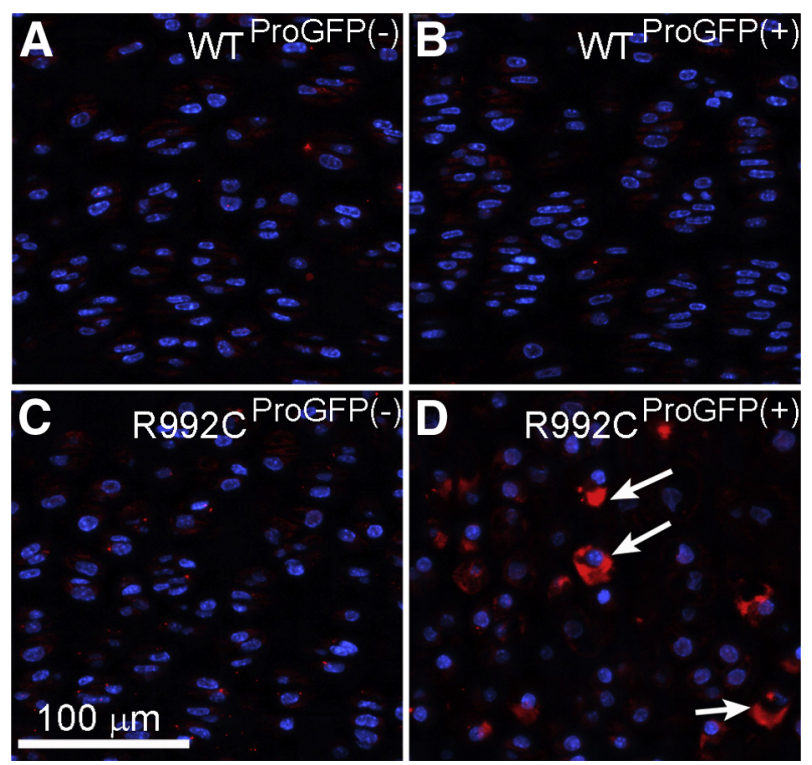

Figure 10 BiP-specific immunostaining of growth plates of 2-week-old WT (A and B) and R992C (C and D) mice. D: Arrows indicate the BiPpositive cells.

\section{Proliferation of Chondrocytes}

The relative numbers of dividing chondrocytes were determined by calculating the percentages of PCNA-positive cells in sections from control and mutant growth plates (Figure 13, A-C). The percentage of cells undergoing division was significantly lower in the $\mathrm{R} 992 \mathrm{C}^{\mathrm{ProGFP}(+)}$ mice in both the newborn and 10-week-old groups (Figure 13D). In the 10-week-old ${ }^{\operatorname{Dox}} \mathrm{R} 992 \mathrm{C}^{\operatorname{ProGFP}(+)}$ mice in which the expression of the mutant transgene was switched off, the percentage of proliferating cells was the same as in the agematched $\mathrm{WT}^{\text {ProGFP(+) }}{ }^{2}$ and the ${ }^{\text {Dox }} \mathrm{WT}^{\text {ProGFP(+) }}{ }^{\text {controls. }}$

\section{Discussion}

Here, we investigated the molecular and cellular aspects of the pathomechanisms associated with a relatively mild form of SED caused by the R992C substitution in collagen II. A transgenic mouse model was designed in a way that allows for the expression of the $\mathrm{WT}^{\text {ProGFP }}$ or the $\mathrm{R}^{\text {99 }} \mathrm{C}^{\text {ProGFP }}$ transgene in a conditional fashion. All elements of this novel model such as DNA constructs encoding the WT and the mutant collagen II variants and mice harboring the Col2a1cre or tTA were tested, and their utility to serve as elements of conditional expression models was well established, as described. $^{21,22,25,30-37}$

A few critical characteristics of the Tet-off model presented here render it biologically relevant, namely: i) The expression of the R992 $\mathrm{C}^{\text {ProGFP }}$, but not the WT ProGFP transgene, was associated with skeletal abnormalities; ii) Only the R992C ${ }^{\text {ProGFP(+) }}$ mice, but not their R992C ${ }^{\text {ProGFP(-) }}$ littermates, showed alteration of skeletal growth; iii)
Maintaining the ${ }^{\text {Dox }} \mathrm{R} 992 \mathrm{C}^{\operatorname{ProGFP}(+)}$ mice in Tet-off conditions in which the expression of the mutant transgene was blocked eliminated development of skeletal aberrations; and iv) The cellular localization of the GFP-tagged exogenous molecules was consistent with their chondrocyte-specific expression.

The transgenic model for the expression of the R992C ProGFP molecules recapitulates a number of critical characteristics seen previously in less complex cell-based models. ${ }^{21,22}$ Specifically, we confirmed at the organismal level the relationship among the misfolding of the thermolabile collagen II mutations, their excessive intracellular accumulation, reduced secretion, and the occurrence of ER stress. ${ }^{21,22}$ This basic pathomechanism was fundamental for triggering complex consequences that lead to the alteration of skeletal growth demonstrated here by the shortening of vertebrae, long bones, and skull. Although statistically significant, the differences in the length of skeletal elements seen among 10-week-old mutant and WT mice were relatively small. Comparing 6-month-old WT and mutant littermates, however, these differences were more prominent, thereby suggesting that the consequences of the R992C mutation persist through the entire postnatal development of skeletal tissue.

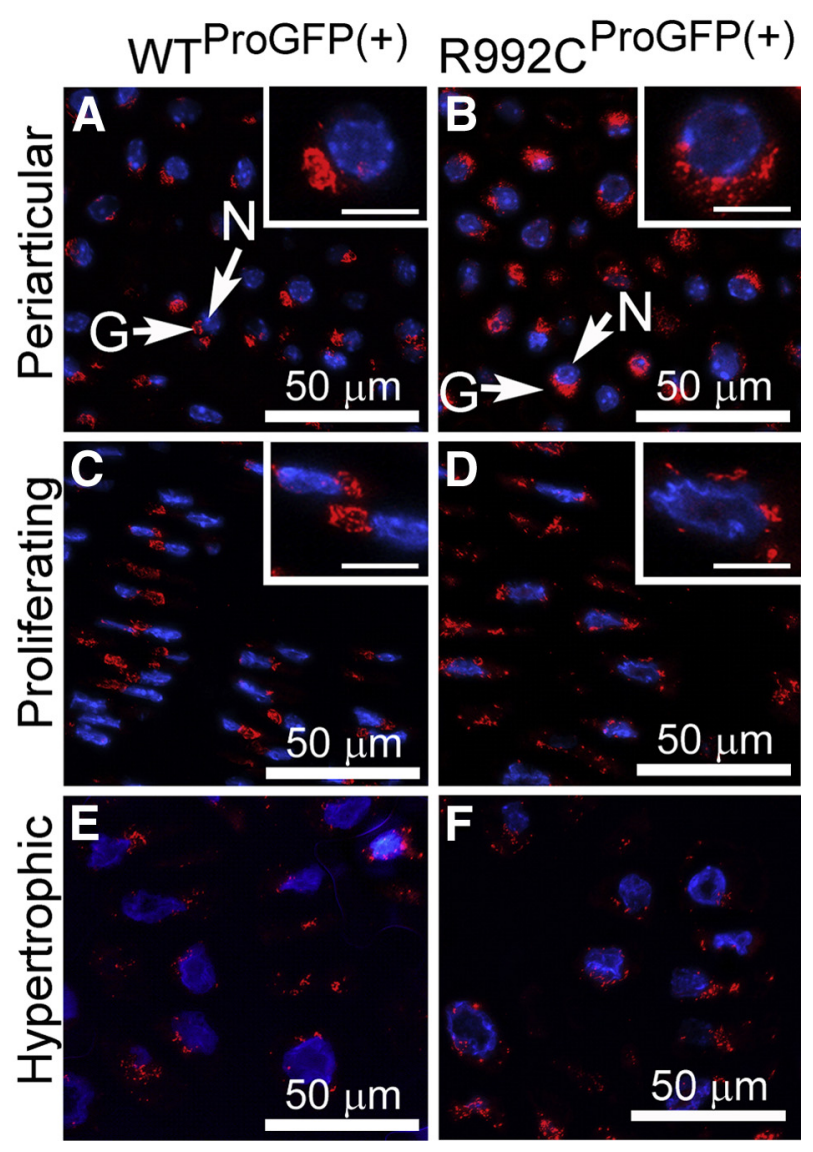

Figure 11 Analysis of the Golgi apparatus-nucleus polarity of growth plate chondrocytes in newborn WT ${ }^{\operatorname{ProGPP}(+)}(\mathbf{A}, \mathbf{C}$, and $\mathbf{E})$ and $\operatorname{R992C}^{\text {ProGFP(+) }}$ (B, D, and $\mathbf{F})$ mice. Golgi apparatus $(\mathrm{G})$ and nuclei $(\mathrm{N})$ are indicated. Insets include detailed views of selected cells. Scale bars: $100 \mu \mathrm{m}$ (insets). 


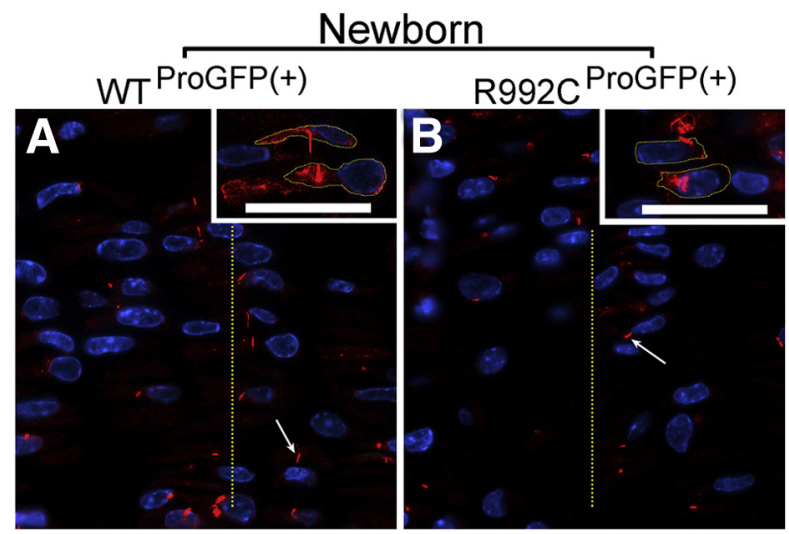

10 weeks

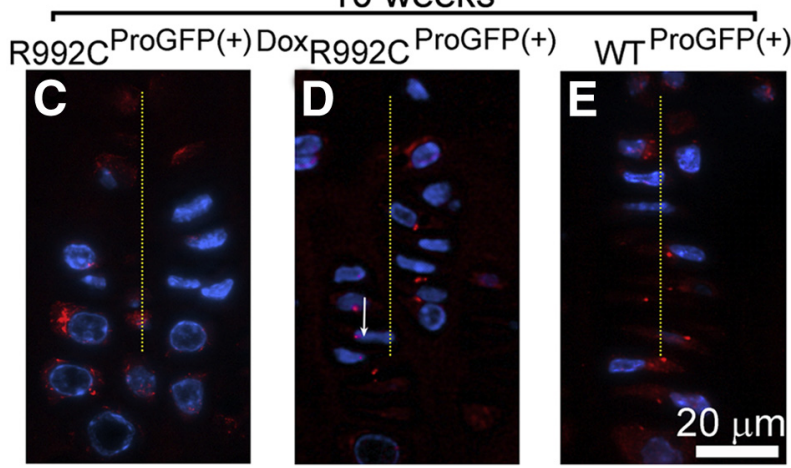

Figure 12 Acetylated tubulin-specific immunostaining of primary cilia in chondrocytes of newborn (A and $\mathbf{B}$ ) and 10-week-old (C, D, and $\mathbf{E}$ ) mice. The 10 -week-old mice were maintained in the presence or the absence of doxycycline (Dox). Dotted lines approximate the long axis of the analyzed tibiae. The insets depict a close view of chondrocytes cilia. Arrows indicate positions of selected primary cilia. Scale bars: $20 \mu \mathrm{m}$ (insets).

Here, we focused on analyzing the growth plates whose organization was disrupted in mice expressing the R992C mutation. As demonstrated by analyses of a number of transgenic mice harboring various collagen II mutations, the disorganization of growth plates is a common consequence associated with the expression of mutant collagen II molecules. ${ }^{18,19,24,51}$ The aberration of the organization of growth plates is also a common feature associated with skeletal dysplasias caused by mutations in other cartilaginous macromolecules. For instance, growth plate alterations were demonstrated in pseudoachondroplasia caused by mutations in cartilage oligomeric matrix protein, and metaphyseal chondrodysplasia type Schmid caused by mutations in collagen $X{ }^{52,53}$ Even though these diseases are caused by mutations in distinct structural proteins, the alterations of affected growth plates share similar features such as the occurrence of ER stress, disorganization of the spatial organization of chondrocytes, and changes in their zonal arrangement. Thus, such a universal response of cartilaginous tissue to the alterations of its individual components strongly indicates the need for the proper structure and harmonized functions of all of them through the entire process of building and remodeling of a complex architecture of growing bone.
The typical columnar organization of chondrocytes in growth plates is an effect of complex processes that involve divisions of chondrocytes and their subsequent movements and rotations. ${ }^{9}$ In essence, two main elements are crucial to positioning and maintaining the correct spatial arrangement of chondrocytes: a correctly assembled extracellular threedimensional scaffold and a cellular sensing system able to receive and process biomechanical cues imposed by forces
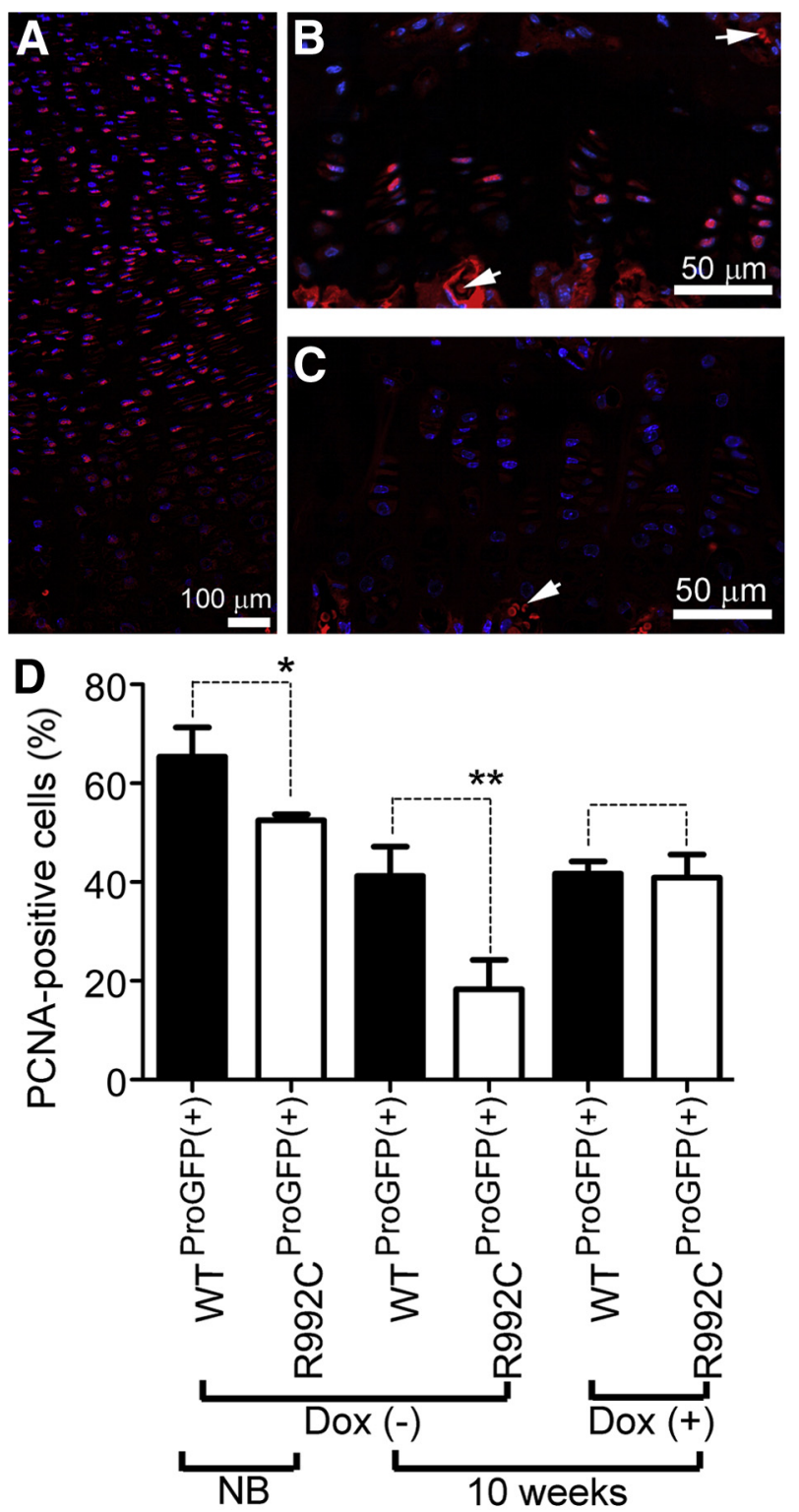

Figure 13 Analysis of proliferation of chondrocytes. A: An example of PCNA-positive chondrocytes seen in newborn mice. B: An example of PCNApositive chondrocytes seen in 10-week-old mice. C: Nuclei of chondrocytes seen in 10-week-old mice in a specimen that was not treated with the primary anti-PCNA antibody. Arrows indicate blood cells, most likely erythrocytes, visualized in an unspecific way in the bone areas. D: Graphic presentation of the differences in proliferation of growth plate chondrocytes from newborn and 10-week-old mice. The mice were maintained in the presence or the absence of doxycycline (Dox). Dotted lines indicate specific pairs of groups whose proliferation was compared. ${ }^{*} P<0.05,{ }^{*} P<0.01$ for the $\mathrm{R}_{9} 2 \mathrm{C}^{\text {ProGFP }(+)}$ mice compared with the $\mathrm{WT}^{\mathrm{ProGFP}(+)}$ control. 
that act on skeletal tissues. Perturbation of these elements leads to the alteration of skeletal development. ${ }^{15}$

Here, we have demonstrated that in the R992C ${ }^{\operatorname{ProGFP}(+)}$ mice, the extracellular network of collagen II fibrils was not correctly formed. Detailed assays indicated overall reduction of collagen II deposited in the ECM of the growth plates of affected mice. Although the model mice expressed the endogenous WT collagen II chains, this reduction was elaborated by coassembly of these chains with exogenous mutant partners, thereby leading to the formation of aberrant triple-helical collagen II molecules. ${ }^{54,55}$ Moreover, observation of the disturbed organization of collagen fibril deposits present among columns of growth plate chondrocytes suggests the formation of poor architecture of the extracellular scaffold in the presence of mutant collagen II molecules. It is predicted that quantitative and qualitative aberrations of collagen II matrices could alter their mechanical and biological functions such as the ability to properly mediate cell-matrix signaling.

Chondrocytes maintain the cell-matrix communication via specific receptors among which integrins, discoidin domain receptors, NG2, CD44, and annexin 5 play an important role. ${ }^{56}$ Although these receptors are detected through the entire surface of cell membrane of chondrocytes, the $\alpha 2, \alpha 3$, and $\beta 1$ integrins and NG2 were also located on primary cilia. ${ }^{14}$ By interlacing with elements of the ECM, primary cilia play a critical role in sensing and transmitting mechanical cues from the cartilaginous environment. Here, we demonstrated that the majority of primary cilia in growth plate chondrocytes seen in newborn $\mathrm{WT}^{\mathrm{ProGFP}(+)}$ mice were correctly organized by being aligned in parallel with the longitudinal axis of the analyzed bones. By contrast, in the corresponding cartilage regions of the $\mathrm{R} 992 \mathrm{C}^{\mathrm{ProGFP}(+)}$ mice, the parallel orientation of primary cilia was not strictly maintained. In 10-week-old ${ }^{\text {Dox }} \mathrm{R} 992 \mathrm{C}^{\text {ProGFP(+) }}$ mice in which the expression of the R992C molecules was blocked, the orientation of primary cilia was comparable to that of the WT control. These results clearly suggest that alterations of cilia orientation were a result of the presence of mutant collagen II molecules. It is not clear, however, whether alterations of cilia orientation were a result of the aberrant structure of the extracellular fibrillar collagen network, with which cilia interact, or if these alterations were associated with excessive intracellular accumulation of mutant molecules. We postulate that both mechanisms are possible. First, by using collagen-specific staining, we demonstrated that the architecture of the collagen matrix is abnormal, thereby indicating that cilia may not be able to recognize it properly. Second, we showed that the chondrocytes harboring mutant collagen II molecules experience ER stress and that their Golgi apparatus-nucleus polarization is not strictly maintained. These characteristics of affected chondrocytes may alter, not only the cilia orientation, but also their length. Indeed, the length of measured cilia present in mice harboring the mutant collagen II molecules was significantly reduced. The consequences of primary cilia shortening as a result of cellular stress could be debilitating. Specifically, the changes in cilia length could impact sensing and transduction of osmotic and mechanical challenges to chondrocytes, thus reducing the ability of these cells to react correctly to a constantly changing biomechanical environment. ${ }^{57}$ Although the current study does not identify specific stressors acting on the involved chondrocytes, it is possible, however, that the observed ER stress caused by the presence of the misfolded thermolabile R992C mutation may be one of them. In support of this notion are our previous studies done in cell-based models that described the detailed association of the R992C collagen II mutation with ER stress. ${ }^{21,22}$ In the model presented here, cellular stress was indicated by an increase in the content of $\mathrm{BiP}$ in chondrocytes from mutant mice and by their reduced proliferation. ${ }^{58-60}$ Considering the aberrant structures of the collagenous matrix, altered cell-matrix interaction could also be involved in the observed reduction of cell proliferation. This postulation is supported by reports indicating that the contact of chondrocytes with the ECM is critical, not only for their survival and differentiation, but also for their proliferation, and that collagen-specific integrins mediate these key processes. ${ }^{61,62}$ Normalization of the proliferation of chondrocytes in 10-week-old ${ }^{\text {Dox }} \mathrm{R} 992 \mathrm{C}^{\text {ProGFP(+) }}$ mice further confirms the prediction that reduced proliferation seen in corresponding 10-week-old $\mathrm{R} 992 \mathrm{C}^{\operatorname{ProGFP}(+)}$ mice is indeed strongly associated with the presence of the R992C mutation.

As demonstrated by the GM-130-specific and the DNAspecific staining, the polarity of the WT chondrocytes present in the proliferating zones of newborn mice was organized along the Golgi apparatus-nucleus axis. By contrast, in the corresponding zones observed in mutant mice, such polarity was not strictly maintained. Because the Golgi apparatus plays a critical role in processing and directing the secretion of key macromolecules of cartilage, including collagen II, these results may suggest that the secretion and correct deposition of these molecules may be impaired in mutant mice. In support of this postulation is our earlier observation that although the R992C collagen II mutant molecules are secreted from cells, the rate of their secretion is relatively low. ${ }^{21}$ Moreover, the altered polarity of chondrocytes harboring the R992C mutations may also contribute to the observed changes in spatial distribution of cilia whose structural association with the Golgi apparatus is well established. ${ }^{12}$ It was proposed that this association facilitates the functioning of a critical mechanism, whereby primary cilia in chondrocytes serve as a sensory element that translates extracellular information to enable the optimal secretion and deposition of structural elements in the cartilaginous ECM. ${ }^{12}$ In the context of skeletal diseases, this concept is supported by the fact that some skeletal dysplasias are associated with alterations of the described mechanism caused by mutations in primary cilia elements or in the structural proteins of the Golgi apparatus. ${ }^{63-65}$

The presented study investigated selected aspects of a complex pathomechanism that controls a cascade of events triggered by a single amino acid substitution in collagen II. 
Our results indicate that alteration of the extracellular collagen II network and ER stress may negatively impact the orientation and the length of chondrocyte cilia, thereby altering cilia-mediated processes such as proliferation, polarization of chondrocytes, and their spatial organization. Using a novel inducible model for the expression of the mutant and WT transgenes in which switching off the expression of mutant molecules eliminates the disease phenotype provided a meaningful experimental control tool that established the undoubted role of collagen II mutations in the development of the diseased phenotype in analyzed mice. In future experiments, switching off the expression of the mutant transgene at various prenatal and postnatal stages of skeletal development will provide important information on the ability of skeletal tissues formed in the presence of mutant collagens to remodel and regress pathological changes on applying prospective gene and cell-based therapies aimed at reducing the content of mutant molecules. ${ }^{15}$

\section{References}

1. Ballock RT, O'Keefe RJ: The biology of the growth plate. J Bone Joint Surg Am 2003, 85-A:715-726

2. Burgeson RE, Hollister DW: Collagen heterogeneity in human cartilage: identification of several new collagen chains. Biochem Biophys Res Commun 1979, 87:1124-1131

3. Eyre D: Collagen of articular cartilage. Arthritis Res 2002, 4:30-35

4. Blaschke UK, Eikenberry EF, Hulmes DJ, Galla HJ, Bruckner P: Collagen XI nucleates self-assembly and limits lateral growth of cartilage fibrils. J Biol Chem 2000, 275:10370-10378

5. Hagg R, Bruckner P, Hedbom E: Cartilage fibrils of mammals are biochemically heterogeneous: differential distribution of decorin and collagen IX. J Cell Biol 1998, 142:285-294

6. Lefebvre V, Bhattaram P: Vertebrate skeletogenesis. Curr Top Dev Biol 2010, 90:291-317

7. Mackie EJ, Tatarczuch L, Mirams M: The skeleton: a multifunctional complex organ: the growth plate chondrocyte and endochondral ossification. J Endocrinol 2011, 211:109-121

8. Song B, Haycraft CJ, Seo HS, Yoder BK, Serra R: Development of the post-natal growth plate requires intraflagellar transport proteins. Dev Biol 2007, 305:202-216

9. Dodds GS: Row formation and other types of arrangement of cartilage cells in endochondral ossification. Anat Rec 1930, 46:385-399

10. Poole CA, Flint MH, Beaumont BW: Morphology of the pericellular capsule in articular cartilage revealed by hyaluronidase digestion. J Ultrastruct Res 1985, 91:13-23

11. McGlashan SR, Haycraft CJ, Jensen CG, Yoder BK, Poole CA: Articular cartilage and growth plate defects are associated with chondrocyte cytoskeletal abnormalities in Tg737orpk mice lacking the primary cilia protein polaris. Matrix Biol 2007, 26:234-246

12. Poole CA, Jensen CG, Snyder JA, Gray CG, Hermanutz VL, Wheatley DN: Confocal analysis of primary cilia structure and colocalization with the Golgi apparatus in chondrocytes and aortic smooth muscle cells. Cell Biol Int 1997, 21:483-494

13. Satir P, Christensen ST: Overview of structure and function of mammalian cilia. Annu Rev Physiol 2007, 69:377-400

14. McGlashan SR, Jensen CG, Poole CA: Localization of extracellular matrix receptors on the chondrocyte primary cilium. J Histochem Cytochem 2006, 54:1005-1014

15. Arnold WV, Fertala A: Skeletal diseases caused by mutations that affect collagen structure and function. Int J Biochem Cell Biol 2013, 45:1556-1567
16. McLean W, Olsen BR: Mouse models of abnormal skeletal development and homeostasis. Trends Genet 2001, 17:S38-S43

17. Savontaus M, Metsranta M, Vuorio E: Retarded skeletal development in transgenic mice with a type II collagen mutation. Am J Pathol 1996, 149:2169-2182

18. Gaiser KG, Maddox BK, Bann JG, Boswell BA, Keene DR, Garofalo S, Horton WA: Y-position collagen II mutation disrupts cartilage formation and skeletal development in a transgenic mouse model of spondyloepiphyseal dysplasia. J Bone Miner Res 2002, 17:39-47

19. Barbieri O, Astigiano S, Morini M, Tavella S, Schito A, Corsi A, Di Martino D, Bianco P, Cancedda R, Garofalo S: Depletion of cartilage collagen fibrils in mice carrying a dominant negative Col2a1 transgene affects chondrocyte differentiation. Am J Physiol Cell Physiol 2003, 285:C1504-C1512

20. Donahue LR, Chang B, Mohan S, Miyakoshi N, Wergedal JE, Baylink DJ, Hawes NL, Rosen CJ, Ward-Bailey P, Zheng QY, Bronson RT, Johnson KR, Davisson MT: A missense mutation in the mouse Col2a1 gene causes spondyloepiphyseal dysplasia congenita, hearing loss, and retinoschisis. J Bone Miner Res 2003, 18:1612-1621

21. Chung HJ, Jensen DA, Gawron K, Steplewski A, Fertala A: R992C (p.R1192C) substitution in collagen II alters the structure of mutant molecules and induces the unfolded protein response. J Mol Biol 2009, 390:306-318

22. Jensen DA, Steplewski A, Gawron K, Fertala A: Persistence of intracellular and extracellular changes after incompletely suppressing expression of the R789C (p.R989C) and R992C (p.R1192C) collagen II mutants. Hum Mutat 2011, 32:794-805

23. Committee for the Update of the Guide for the Care and Use of Laboratory Animals; National Research Council: Guide for the Care and Use of Laboratory Animals: Eighth Edition. Washington, DC, National Academies Press, 2011

24. Hintze V, Steplewski A, Ito H, Jensen DA, Rodeck U, Fertala A: Cells expressing partially unfolded R789C/p.R989C type II procollagen mutant associated with spondyloepiphyseal dysplasia undergo apoptosis. Hum Mutat 2008, 29:841-851

25. Ito H, Rucker E, Steplewski A, McAdams E, Brittingham RJ, Alabyeva T, Fertala A: Guilty by association: some collagen II mutants alter the formation of ECM as a result of atypical interaction with fibronectin. J Mol Biol 2005, 352:382-395

26. Cho JY, Grant TD, Lunstrum GP, Horton WA: Col2-GFP reporter mouse- a new tool to study skeletal development. Am J Med Genet 2001, 106:251-253

27. Grant TD, Cho J, Ariail KS, Weksler NB, Smith RW, Horton WA: Col2-GFP reporter marks chondrocyte lineage and chondrogenesis during mouse skeletal development. Dev Dyn 2000, 218:394-400

28. Canty-Laird EG, Lu Y, Kadler KE: Stepwise proteolytic activation of type I procollagen to collagen within the secretory pathway of tendon fibroblasts in situ. Biochem J 2012, 441:707-717

29. Hojima Y, van der Rest M, Prockop DJ: Type I procollagen carboxylterminal proteinase from chick embryo tendons. Purification and characterization. J Biol Chem 1985, 260:15996-16003

30. Li L, Tasic B, Micheva KD, Ivanov VM, Spletter ML, Smith SJ, Luo L: Visualizing the distribution of synapses from individual neurons in the mouse brain. PLoS One 2010, 5:e11503

31. Grover J, Roughley PJ: Generation of a transgenic mouse in which Cre recombinase is expressed under control of the type II collagen promoter and doxycycline administration. Matrix Biol 2006, 25:158-165

32. Neuhold LA, Killar L, Zhao W, Sung ML, Warner L, Kulik J, Turner J, Wu W, Billinghurst C, Meijers T, Poole AR, Babij P, DeGennaro LJ: Postnatal expression in hyaline cartilage of constitutively active human collagenase-3 (MMP-13) induces osteoarthritis in mice. J Clin Invest 2001, 107:35-44

33. Posey KL, Veerisetty AC, Liu P, Wang HR, Poindexter BJ, Bick R, Alcorn JL, Hecht JT: An inducible cartilage oligomeric matrix protein mouse model recapitulates human pseudoachondroplasia phenotype. Am J Pathol 2009, 175:1555-1563 
34. Blaney Davidson EN, Vitters EL, Bennink MB, van Lent PL, van Caam AP, Blom AB, van den Berg WB, van de Loo FA, van der Kraan PM: Inducible chondrocyte-specific overexpression of BMP2 in young mice results in severe aggravation of osteophyte formation in experimental OA without altering cartilage damage. Ann Rheum Dis 2014

35. Sakai K, Hiripi L, Glumoff V, Brandau O, Eerola R, Vuorio E, Bosze Z, Fassler R, Aszodi A: Stage-and tissue-specific expression of a Col2a1Cre fusion gene in transgenic mice. Matrix Biol 2001, 19:761-767

36. Ovchinnikov DA, Deng JM, Ogunrinu G, Behringer RR: Col2a1directed expression of Cre recombinase in differentiating chondrocytes in transgenic mice. Genesis 2000, 26:145-146

37. Akiyama H, Chaboissier MC, Martin JF, Schedl A, de Crombrugghe B: The transcription factor Sox 9 has essential roles in successive steps of the chondrocyte differentiation pathway and is required for expression of Sox5 and Sox6. Genes Dev 2002, 16:2813-2828

38. Gossen M, Freundlieb S, Bender G, Muller G, Hillen W, Bujard H: Transcriptional activation by tetracyclines in mammalian cells. Science $1995,268: 1766-1769$

39. Moutier R, Tchang F, Caucheteux SM, Kanellopoulos-Langevin C: Placental anomalies and fetal loss in mice, after administration of doxycycline in food for tet-system activation. Transgenic Res 2003, 12: 369-373

40. Kistner A, Gossen M, Zimmermann F, Jerecic J, Ullmer C, Lubbert H, Bujard H: Doxycycline-mediated quantitative and tissuespecific control of gene expression in transgenic mice. Proc Natl Acad Sci U S A 1996, 93:10933-10938

41. Fertala A, Sieron AL, Ganguly A, Li SW, Ala-Kokko L, Anumula KR, Prockop DJ: Synthesis of recombinant human procollagen II in a stably transfected tumour cell line (HT1080). Biochem J 1994, 298:31-37

42. Somerville JM, Aspden RM, Armour KE, Armour KJ, Reid DM: Growth of C57BL/6 mice and the material and mechanical properties of cortical bone from the tibia. Calcif Tissue Int 2004, 74:469-475

43. Brodt MD, Ellis CB, Silva MJ: Growing C57B1/6 mice increase whole bone mechanical properties by increasing geometric and material properties. J Bone Miner Res 1999, 14:2159-2166

44. Chambers MG, Kuffner T, Cowan SK, Cheah KS, Mason RM: Expression of collagen and aggrecan genes in normal and osteoarthritic murine knee joints. Osteoarthritis Cartilage 2002, 10:51-61

45. Kveiborg M, Albrechtsen R, Rudkjaer L, Wen G, DamgaardPedersen K, Wewer UM: ADAM12-S stimulates bone growth in transgenic mice by modulating chondrocyte proliferation and maturation. J Bone Miner Res 2006, 21:1288-1296

46. Aizawa T, Kokubun S, Tanaka Y: Apoptosis and proliferation of growth plate chondrocytes in rabbits. J Bone Joint Surg Br 1997, 79:483-486

47. Tajima Y, Kato K, Maruyama S, Hosoi K: In vivo modulation of proliferating cell nuclear antigen in growth plate chondrocytes from normal, hypophysectomized, growth hormone-treated hypophysectomized rats: a comparative immunohistochemical study with image analysis. J Histochem Cytochem 1996, 44:713-720

48. Fertala A, Ala-Kokko L, Wiaderkiewicz R, Prockop DJ: Collagen II containing a Cys substitution for arg-alpha1-519. Homotrimeric monomers containing the mutation do not assemble into fibrils but alter the selfassembly of the normal protein. J Biol Chem 1997, 272:6457-6464

49. Sieron AL, Fertala A, Ala-Kokko L, Prockop DJ: Deletion of a large domain in recombinant human procollagen II does not alter the thermal stability of the triple helix. J Biol Chem 1993, 268:21232-21237
50. Keene DR, Oxford JT, Morris NP: Ultrastructural localization of collagen types II, IX, and XI in the growth plate of human rib and fetal bovine epiphyseal cartilage: type XI collagen is restricted to thin fibrils. J Histochem Cytochem 1995, 43:967-979

51. Arita M, Li SW, Kopen G, Adachi E, Jimenez SA, Fertala A: Skeletal abnormalities and ultrastructural changes of cartilage in transgenic mice expressing a collagen II gene (COL2A1) with a Cys for Arg-alpha1-519 substitution. Osteoarthritis Cartilage 2002, 10: 808-815

52. Hecht JT, Hayes E, Haynes R, Cole WG: COMP mutations, chondrocyte function and cartilage matrix. Matrix Biol 2005, 23 : $525-533$

53. Ho MS, Tsang KY, Lo RL, Susic M, Makitie O, Chan TW, Ng VC, Sillence DO, Boot-Handford RP, Gibson G, Cheung KM, Cole WG, Cheah KS, Chan D: COL10A1 nonsense and frame-shift mutations have a gain-of-function effect on the growth plate in human and mouse metaphyseal chondrodysplasia type Schmid. Hum Mol Genet 2007, 16:1201-1215

54. Prockop DJ: Osteogenesis imperfecta: phenotypic heterogeneity, protein suicide, short and long collagen. Am J Hum Genet 1984, 36: 499-505

55. Prockop DJ, Kivirikko KI: Collagens: molecular biology, diseases, and potentials for therapy. Annu Rev Biochem 1995, 64:403-434

56. Woods A, Wang G, Beier F: Regulation of chondrocyte differentiation by the actin cytoskeleton and adhesive interactions. J Cell Physiol 2007, 213:1-8

57. Rich DR, Clark AL: Chondrocyte primary cilia shorten in response to osmotic challenge and are sites for endocytosis. Osteoarthritis Cartilage 2012, 20:923-930

58. Pirog-Garcia KA, Meadows RS, Knowles L, Heinegard D, Thornton DJ, Kadler KE, Boot-Handford RP, Briggs MD: Reduced cell proliferation and increased apoptosis are significant pathological mechanisms in a murine model of mild pseudoachondroplasia resulting from a mutation in the C-terminal domain of COMP. Hum Mol Genet 2007, 16:2072-2088

59. Tsang KY, Chan D, Bateman JF, Cheah KS: In vivo cellular adaptation to ER stress: survival strategies with double-edged consequences. J Cell Sci 2010, 123:2145-2154

60. Gualeni B, Rajpar MH, Kellogg A, Bell PA, Arvan P, BootHandford RP, Briggs MD: A novel transgenic mouse model of growth plate dysplasia reveals that decreased chondrocyte proliferation due to chronic ER stress is a key factor in reduced bone growth. Dis Model Mech 2013, 6:1414-1425

61. Svoboda KK: Chondrocyte-matrix attachment complexes mediate survival and differentiation. Microsc Res Tech 1998, 43:111-122

62. Grashoff C, Aszodi A, Sakai T, Hunziker EB, Fassler R: Integrinlinked kinase regulates chondrocyte shape and proliferation. EMBO Rep 2003, 4:432-438

63. Huber C, Cormier-Daire V: Ciliary disorder of the skeleton. Am J Med Genet C Semin Med Genet 2012, 160C:165-174

64. Smits P, Bolton AD, Funari V, Hong M, Boyden ED, Lu L, Manning DK, Dwyer ND, Moran JL, Prysak M, Merriman B, Nelson SF, Bonafe L, Superti-Furga A, Ikegawa S, Krakow D, Cohn DH, Kirchhausen T, Warman ML, Beier DR: Lethal skeletal dysplasia in mice and humans lacking the golgin GMAP-210. N Engl J Med 2010, 362:206-216

65. Haycraft CJ, Serra R: Cilia involvement in patterning and maintenance of the skeleton. Curr Top Dev Biol 2008, 85:303-332 